\title{
COGNITION
}

\section{Children's command of quantification}

\author{
Jeffrey Lidz ${ }^{\mathrm{a}, 1}$, Julien Musolino ${ }^{\mathrm{b}, 1, *}$ \\ ${ }^{a}$ Department of Linguistics, Northwestern University, 2016 Sheridan Rd., Evanston, IL 60208-4090, USA \\ ${ }^{\mathrm{b}}$ Department of Speech and Hearing Sciences, Indiana University, 200 S. Jordan Avenue, \\ Bloomington, IN 47405-7002, USA
}

Received 16 December 2001; received in revised form 2 January 2002; accepted 8 February 2002

\begin{abstract}
In this article we present data from two sets of experiments designed to investigate how children and adult speakers of English and Kannada (Dravidian) interpret scopally ambiguous sentences containing numerally quantified noun phrases and negation (e.g. Donald didn't find two guys). We use this kind of sentence as a way to find evidence in children's linguistic representations for the hierarchical structure and the abstract relations defined over these structures (in particular, the relation of c-command) that linguists take to be at the core of grammatical knowledge. Specifically, we uncover the existence of systematic differences in the way that children and adult speakers resolve these ambiguities, independent of the language they speak. That is, while adults can easily access either scope interpretation, 4-year-old children display a strong preference for the scopal interpretation of the quantified elements which corresponds to their surface syntactic position. Crucially, however, we show that children's interpretations are constrained by the surface hierarchical relations (i.e. the c-command relations) between these elements and not by their linear order. Children's non-adult interpretations are therefore informative about the nature of the syntactic representations they entertain and the rules they use to determine the meaning of a sentence from its structure. (C) 2002 Elsevier Science B.V. All rights reserved.
\end{abstract}

Keywords: Language acquisition; Cross-linguistic; Ambiguity resolution; Quantifier scope; Negation; Ccommand; Kannada

\section{Introduction}

In this paper we investigate children's knowledge of the linguistic principles governing the interpretation of the quantificational expressions of their language (e.g. no man, two

\footnotetext{
* Corresponding author. Fax: +1-812-855-5531.

E-mail address: musolino@indiana.edu (J. Musolino).

1 The authors are engaged in a continuing collaboration in which the order of names alternates from one paper to the next. The authors contributed equally to the work reported here.
} 
women). The study of natural language quantifiers belongs to a long tradition of philosophical inquiry concerned with the logical analysis of language that can be traced back to antiquity. A well-known problem raised by quantificational expressions is the inherently non-referential nature of their meaning; a fact that Lewis Carroll understood all too well:

"Who did you pass on the road?" the King went on, holding out his hand to the Messenger for some more hay.

"Nobody" said the Messenger.

"Quite right", said the King: "this young lady saw him too. So of course Nobody walks slower than you".

"I do my best", the Messenger said in a sullen tone. "I'm sure that nobody walks much faster than I do!"

"He can't do that", said the King, "or else he'd have been here first...".

\section{- Lewis Carroll, Through the Looking-Glass and What Alice Found There}

The King's error in the passage above was to treat nobody as though it referred to an individual whereas in fact, quantified expressions express generalizations about sets of individuals. So, the sentence Nobody passed the Messenger expresses the idea that the intersection of the set of individuals and the set of entities having the property of passing the Messenger is the null set. Another important property of quantifiers, guiding the King's reasoning in Lewis Carroll's example, is the rich set of inferences to which they give rise.

In addition to vexing philosophers, logicians and kings, quantified expressions also raise serious psychological issues, in particular in the domain of conceptual development and language acquisition. Consider the problem of a learner trying to determine the meanings of words. The learner needs to avoid the problem faced by the King in our example above. That is, learners must avoid treating quantifiers as referring to individuals. But this should only complicate their task: after all, once learners have realized that quantifiers are nonreferential, it is unclear what kinds of perceptual regularities they could possibly associate with such expressions. To complicate matters further, the conceptual generalizations expressed by quantified expressions are abstract, and so the learner's ability to map these concepts onto phonological form depends on cognitive development having reached the point at which such concepts can be mastered and put to use.

In the psychological literature, children's comprehension of quantifiers has traditionally been examined as a means of assessing their logical competence. To be sure, understanding the development of reasoning necessitates a proper appreciation of the development of the logical vocabulary available in natural language and the kinds of representations that it is associated with. In their classic studies on the development of logical competence, Inhelder and Piaget $(1958,1964)$ examined children's understanding of the universal quantifier in a number of class inclusion tasks. What they found was that children do not understand sentences containing the universal quantifier until the age of 7 or 8 which, in the Piagetian framework, corresponds to the onset of concrete operational reasoning. Inhelder and Piaget attributed children's misunderstanding of the universal quantifier to a lack of ability to divide groups of objects into separate classes.

In recent years, children's comprehension of sentences containing quantified expres- 
sions has received a good deal of attention from investigators in the field of linguistics (see Crain, 2000 for a review). This renewed interest coincides with recent theoretical developments in the study of formal properties of quantifiers (Barwise \& Cooper, 1981; Keenan \& Stavi, 1986; van Benthem, 1986) and was motivated in part by a desire to begin to map out the development of children's knowledge of the principles underlying natural language semantics. The observation that emerges from these studies is that preschool children often fail to interpret statements or questions containing quantified expressions the way adult speakers do. For example, Philip and Aurelio (1991) found that when presented with a picture showing three mice each in a cup and one extra cup without a mouse and asked of that picture "Is every mouse in a cup?" 3-5-year-old preschool children often answered 'no' and pointed to the empty cup. Similar findings, reminiscent of Piaget's original observations, have been reported by a number of investigators (Bucci, 1978; Donaldson \& Lloyd, 1974; Inhelder \& Piaget, 1964) and have appeared under various labels such as "quantifier spreading", "symmetrical reading" or "conversion" (see Philip, 1996). Moreover, this phenomenon has been studied in a variety of languages including English, French, Chinese, Japanese, Dutch and Catalan (for a review, see Philip, 1995).

While Piaget and his collaborators viewed children's non-adult interpretations of quantified expressions as reflecting a problem at the conceptual level, the studies cited above typically regard children's difficulties with quantifiers as stemming from their immature linguistic representations. For example, Bucci (1978) proposed that statements of the form 'All As are Bs' are often parsed by children and by adults as simple strings of unordered words lacking any syntactic structure. Philip (1995) offered a semantic explanation, arguing that the "symmetrical interpretation" observed in preschool children corresponds to a linguistic representation in which the child over-generalizes a tendency to quantify over individual events rather than individual objects. This latter position is rejected by Crain et al. (1996) who argued that children have full adult linguistic competence in the domain of universal quantification. According to these authors, earlier observations of children's non-adult behavior in tasks involving the comprehension of universally quantified propositions are pragmatic in nature; they are due to violations of the felicity conditions associated with the use of such expressions.

As noted by Brooks and Braine (1996), the vast majority of studies on children's comprehension of quantified expressions have focused almost exclusively on the distributional reading of universal quantifiers. However, the set of natural language quantifiers is not limited to elements such as all and every. In order to gain a broader understanding of children's knowledge of the complex array of linguistic principles underlying the interpretation of quantificational elements it is therefore necessary to look beyond children's comprehension of the universal quantifier. This is what we propose to do in the present article. We present here data from two sets of experiments designed to investigate how children and adult speakers of English and Kannada (Dravidian) interpret ambiguous sentences containing numerally quantified noun phrases (e.g. two horses) and negation. In addition to producing a more detailed picture of development, our goal is twofold: for adults, our aim is to determine whether the intuitions of linguists about the possible interpretations of these sentences can be verified experimentally. To the extent that this is the case, we then ask when children become aware of the complex mapping between syntax and semantics required for the interpretation of these linguistic 
expressions. Anticipating the results, we uncover in this domain as well the existence of systematic differences in the way that preschool children and adults interpret sentences containing these expressions. We suggest that children's non-adult interpretations have psychological implications for the abstract format of the linguistic representations they entertain. We show that these non-adult interpretations are informative about children's syntactic representations and the rules they use to determine the meaning of a sentence from its structure.

To preface the experimental sections of our study, we lay out some important facts concerning fundamental properties of language and we introduce the technical vocabulary later used to describe the linguistic phenomena we shall be concerned with. We then review a number of pertinent findings on children's and adults' comprehension of quantificational expressions. Finally, we present a set of experiments in which children and adult speakers of English and Kannada were asked to interpret sentences containing multiple quantificational elements.

\section{Linguistic background}

There are two facts about language which seem to us to be uncontroversial. First, sentences have a hierarchical structure. The words in a sentence are not strung together in a list, but rather are composed into nested constituents above the word level. Second, languages exhibit a phenomenon which, following Chomsky (1995), we refer to as displacement: certain elements in a sentence are not interpreted entirely in the positions in which they appear.

\subsection{Hierarchy}

Two of the central conclusions of the foundational work by Chomsky (1957) in syntax are that linguistic representations are hierarchical and that the rules of syntax make reference to this hierarchy. A sentence like (1) is not just a string of words, but rather can be represented as a nested tree structure in which words combine to form phrases and these phrases combine to form larger phrases, as in (2).

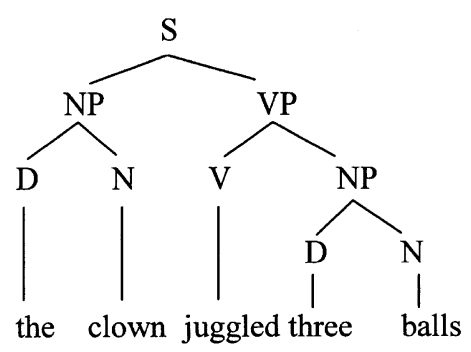


Not only are linguistic expressions structured, but the rules and constraints that apply to these expressions also make reference to this structure. Consider the following contrasts:

(3) a. Hillary $y_{i}$ thinks she $e_{i}$ won the election

b. * She e $_{\mathrm{i}}$ thinks that Hillary $\mathrm{i}_{\mathrm{i}}$ won the election ${ }^{2}$

c. After Bill embarrassed her $r_{i}$, Hillary $y_{i}$ won the election

The contrast between (3a) and (3b) illustrates that there are constraints determining when a pronoun, like she, and a referential expression, like Hillary, can refer to the same entity. This constraint is not based on precedence, as can be seen from examining (3c) in which the pronoun precedes the referential expression. The appropriate generalization becomes clear when we examine the structure underlying (3a) and (3b).

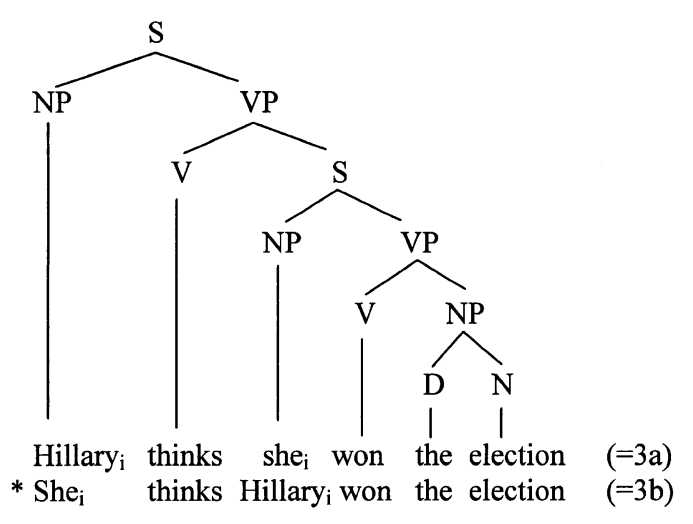

What rules out ( $3 \mathrm{~b}$ ) is a constraint barring a pronoun from being interpreted as identical in reference to an expression that is contained in the smallest nontrivial constituent containing the pronoun itself. Here, the smallest nontrivial constituent containing the matrix subject is the entire sentence and so a pronoun in that position cannot be interpreted as coreferential with anything else in the sentence. In the structure underlying (3a), the smallest nontrivial constituent containing the pronoun is the embedded S. Since Hillary is not contained within this constituent, coreference with the pronoun is allowed.

This generalization is supported by the observation that if we put the pronoun inside a branching constituent in subject position, coreference is allowed. Here, the smallest constituent containing the pronoun is the subject NP. Since there is no coreferential expression in this constituent, the pronoun is licit.

\footnotetext{
${ }^{2}$ Indices are used to indicate that two NPs are coreferential, i.e. that they refer to the same individual. Within this notation, the asterisk on ( $3 \mathrm{~b}$ ) indicates that an interpretation of that sentence on which the pronoun she and the NP Hillary refer to the same individual is not available.
} 
(5)

Her $_{i}$ husband thinks Hillary ${ }_{i}$ won the election

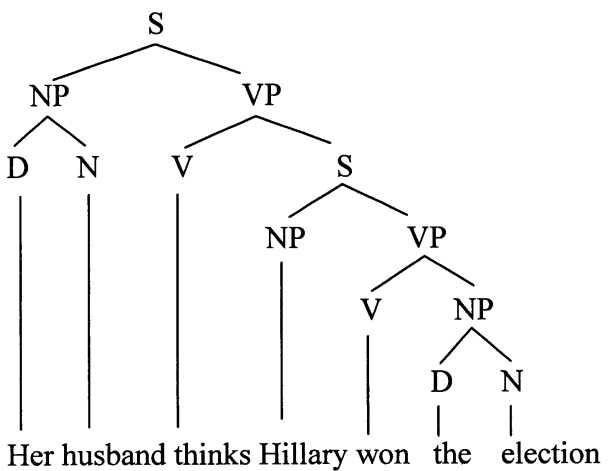

The relation expressed in the previous discussion has been formalized under the notions of c-command and binding (Chomsky, 1981; Reinhart, 1976).

(6) x c-commands y iff

a. the first branching node dominating $\mathrm{x}$ also dominates $\mathrm{y}$

b. $\mathrm{x}$ does not dominate $\mathrm{y}$

c. $\mathrm{x} \neq \mathrm{y}$

(7) $x$ binds $y$ iff

a. $\mathrm{x}$ c-commands $\mathrm{y}$

b. $\mathrm{x}$ and $\mathrm{y}$ are coreferential

The constraint on coreference can now be stated as (8) (Chomsky, 1981; cf. Lasnik, 1976):

A referring expression cannot be bound

Because the referring expression Hillary is c-commanded by and coreferential with the pronoun in (3b), coreference is blocked by the constraint (8). The crucial observation for our purposes is that the explanatory predicate "bind" is based on a relation defined over hierarchical representations, namely c-command. It is only in defining relations over hierarchical representations that we find an explanation for the observed phenomenon, and so we have evidence that these representations exist.

\subsection{Displacement}

As rock-bottom a phenomenon in language as hierarchy is "displacement": certain 
expressions are not interpreted in the positions in which they appear. Consider the observation that the direct object must occur adjacent to the verb in English:

(9) a. Rudy ate the pizza

b. * Rudy ate quickly the pizza

When the direct object is questioned, as in (10), this adjacency requirement is relaxed:

(10) What did Rudy eat __?

In its role as a sentential operator, the $w h$-phrase occurs at the beginning of the sentence. This position is in accord with its interrogative interpretation:

\section{(11) $[$ what $\mathrm{x}][$ Rudy ate $\mathrm{x}]$}

Nonetheless, the wh-phrase is interpreted as the object of the verb and, hence, as though it is in object position. ${ }^{3}$ Intuitively, displacement phenomena illustrate that different kinds of semantic information must be represented in a single structure. When the requirements of different kinds of information are in conflict, only one can be satisfied. ${ }^{4}$

Displacement phenomena come in two varieties. As we have seen, an element that does not occur in an argument position can still be interpreted as an argument. In such cases, it appears that the element has "moved" out of its argument position. Conversely, elements occurring in an argument position are sometimes interpreted as sentential operators, as in (12):
a. Who ate what
b. wh $\langle\mathrm{x}, \mathrm{y}\rangle[\mathrm{x}$ ate $\mathrm{y}]$

Here, the wh-phrase what is interpreted as part of a sentential operator asking for pairs, despite the fact that it has not moved out of its argument position. That is, the appropriate response to (12a) is a set of pairs such that the first element ate the second element (Rudy ate pizza, Bill ate a Big Mac, Hillary ate a sandwich, etc.). What expressions involving multiple $w h$-phrases demonstrate is that displacement does not always involve the appearance of "movement" out of an argument position.

\footnotetext{
${ }^{3}$ This characterization of the phenomenon is independent of the mechanisms that capture it. That is, every theory of interrogation in English must account for the fact that $w h$-expressions are interpreted simultaneously as sentence-level operators and arguments of the predicate, whether this is done by traces (Fiengo, 1977), copies (Chomsky, 1993), slash-categories (Pollard \& Sag, 1994) or other such mechanisms.

${ }^{4}$ Notice that the postulation of traces as real entities represents the simplest of theories in this domain since it allows the displaced element to actually occur in both positions, eliminating a need for statements concerning the resolution of the conflict between argument structure and quantificational structure.
} 


\subsection{Hierarchy, displacement and scope ambiguity}

This kind of "covert" displacement is also exhibited by ambiguities involving the quantificational expressions discussed above, as illustrated in (13a). In an expression like (13a), there are two possible interpretations, given as (13b) and (13c):
a. Everyone didn't smile
b. $\quad \forall x[\neg[\mathrm{x}$ smiled $]]$
c. $\quad \neg[\forall \mathrm{x}[\mathrm{x}$ smiled $]]$

The interpretation represented by (13b) states that everyone has the property that he didn't smile; in other words, no-one smiled. On this interpretation we say that the universal quantifier " $\forall$ " takes scope over negation. The interpretation in (13c) states that it is not the case that everyone smiled; perhaps some people did and some people didn't. Here, negation takes scope over the universal quantifier. The interpretation in (13b) is straightforwardly mapped from the surface syntax of (13a), given in (14):

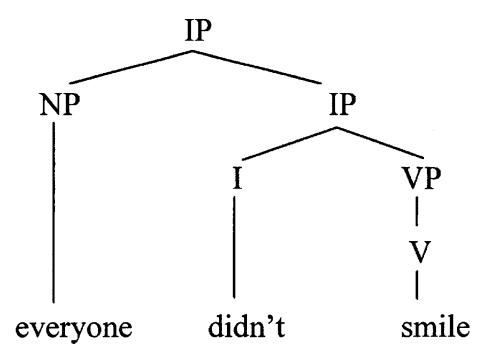

In (14) the NP everyone c-commands the negative clitic n't. Similarly, the semantic counterpart of this expression takes scope over negation in (13b). However, in (13c), negation is interpreted as taking scope over the entire sentence, illustrating again that certain elements are interpreted in positions different from those they occur in in the syntax.

It is important to observe at this point that the representations of both the syntax and the semantics are hierarchical. That is, the representations in (13b) and (13c) are equivalent to the nested tree-structure representations in (15a) and (15b):

a.

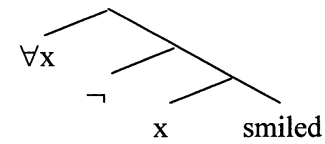

b.<smiles>[X]C([GeH2])C([X])CC</smiles> 
Thus, the scope of the quantificational elements " $\neg$ " and " $\forall$ " is determined by the ccommand relations in the semantic representation. That is, given two quantificational elements $\alpha$ and $\beta, \alpha$ takes scope over $\beta$ if $\alpha$ c-commands $\beta$ in the semantic representation.

Now, the c-command relations holding between two quantificational elements in the surface syntax do not map directly to the c-command relations between these elements in the semantics. This is the covert displacement phenomenon in evidence. As we have seen, the quantificational expression everyone c-commands negation in the surface syntax, but either c-command relation is possible in the semantics.

We can conclude, then, that the surface syntactic structure and the semantic structure are not isomorphic. Data concerning displacement and quantificational ambiguity demonstrate that there is a complex mapping from one kind of structure (surface syntax) to another kind (semantics). It is standard practice in linguistics and philosophy to assume that the meaning of a sentence is a function of the meaning of its parts and the way that they compose (Frege, 1892/1990). So, in order to account for mismatches between the surface syntactic structure of a sentence and its meaning, we can either complicate the rules of syntactic composition or the rules of semantic composition.

Taking the first option, we could treat the quantificational expressions on a par with multiple questions, positing that there are syntactic displacement operations that reposition the quantificational elements in the syntax without phonological consequence (Huang, 1982; May, 1977; McCawley, 1970). This approach simplifies the mapping to the semantics by complicating the syntax. On this view, the syntactic structure directly determines the relevant aspects of interpretation; c-command in the syntax determines scope in the semantics. Taking the second option, we could take the surface syntactic representation to be the input to semantics and develop complex mapping operations to determine the scope of a quantifier independent of its syntactic position (Cooper, 1983; cf. Steedman, 1987). On this view, the syntax and semantics are homomorphic and so the grammar must specify where the two representations diverge. The choice between these approaches may have important theoretical consequences; however, for our purposes it is sufficient to observe that the surface syntax and the semantic structure are not isomorphic, whether this is achieved by a syntactic or a semantic operation inverting the scope of the two operators.

\section{Psycholinguistic background}

Following our description of the formal aspect of quantificational interactions, we now consider children's knowledge of quantification. As we said earlier, we will focus here on scope phenomena involving the interaction between numerally quantified NPs (e.g. two birds) and negation. Our motivation for doing so stems from the fact that the vast majority of existing studies have focused on children's knowledge of universal quantifiers, i.e. all and every, in constructions typically involving a universally and an existentially quantified NP, e.g. every boy saw a squirrel. Another reason to consider interactions between quantified NPs and negation is that there are reasons to believe that scope ambiguities involving these elements employ different formal mechanisms 
than those involving two quantificational NPs (Hornstein, 1984; Reinhart, 1995, 1997). ${ }^{5}$ To the extent that this is the case, studying children's comprehension of sentences involving quantified NPs and negation will produce a map of the development of semantic knowledge which is both broader and finer than that produced by previous work. Finally, we focus our attention on the interaction between numerally quantified NPs and negation in order to ensure that the two scopal orderings can be distinguished. The interpretation of a universal quantifier outside the scope of negation (13b) entails the interpretation in which negation takes wider scope (13c). That is, every situation that makes (13b) true also makes (13c) true. Hence, we can only test one of these readings directly. With numerally quantified NPs, however, this entailment problem does not arise, as we will see below.

In spite of the growing number of studies on children's comprehension of quantificational interactions, relatively few have examined interactions involving quantifiers and negation (but see de Boysson-Bardies \& Bacri, 1977; Drozd \& Philip, 1993; Krämer, 2000; O'Leary \& Crain, 1994; Roeper \& Matthei, 1975; Thornton, 1995). To our knowledge, only one study, by Musolino, Crain, and Thornton (2000), presents a systematic investigation of children's comprehension of quantifier-negation interactions. This study therefore constitutes a natural starting point for our investigation.

Musolino et al. (2000) begin with the observation that sentences containing quantifiers and negation often permit readings which do not directly follow from an isomorphic mapping of surface form to semantic interpretation (see discussion in Section 2 and also Büring, 1997; Horn, 1989; Jackendoff, 1972 among others). Consider the examples below.

$$
\begin{aligned}
& \text { Every horse didn't jump over the fence } \\
& \text { a. } \quad \forall \mathrm{x}[\text { horse }(\mathrm{x}) \rightarrow \neg \text { jump over the fence }(\mathrm{x})] \\
& \text { b. } \quad \neg \forall \mathrm{x} \text { [horse }(\mathrm{x}) \rightarrow \text { jump over the fence }(\mathrm{x})]
\end{aligned}
$$

The detective didn't find some guys

$$
\exists x[\operatorname{guy}(\mathrm{x}) \wedge \neg \operatorname{find}(\text { detective, } \mathrm{x})]
$$

As we pointed out earlier, sentences like (16) are scopally ambiguous. On one interpretation, (16) can be paraphrased as meaning that every horse is such that it didn't jump over the fence. In other words, none of the horses jumped over the fence. Here, the universally

\footnotetext{
${ }^{5}$ For example, when a universal quantifier occurs in object position, it may not take scope over negation:

(i) John didn't borrow every book from the library.

(ii) John didn't borrow two books from the library.
}

The sentence in (i) does not have an inverse scope interpretation, i.e. the interpretation that John borrowed no books from the library. However, the sentence in (ii) clearly does allow the inverse scope interpretation in which there are two books that John didn't borrow. This differs from the situation in which there are two quantificational NPs in a clause. Here, inverse scope is always allowed:

(iii) Some student borrowed every book from my office.

(iv) Some student borrowed two books from my office. 
quantified subject takes scope over negation (abbreviated every $>$ not), as illustrated by the logical representation given in (16a). We call this an isomorphic interpretation because in this case the scope relation between the universally quantified NP and negation coincides with their surface position. Another possible interpretation of (16) is that not all of the horses jumped over the fence. In this case, negation takes scope over the quantified subject (abbreviated not $>$ every), as shown in the logical representation given in (16b). We call this a non-isomorphic interpretation because here negation takes scope over the whole sentence, illustrating again that certain elements are interpreted in positions different from the ones they occupy in surface syntax. Whereas (16) is scopally ambiguous, (17) seems to require a non-isomorphic interpretation expressing the idea that there are some guys that the detective didn't find.

In order to determine whether preschool children are aware of the complex mappings between form and meaning involved in sentences like (16) and (17), Musolino et al. (2000) tested children's comprehension of such sentences using the Truth Value Judgment Task (TVJT) methodology (Crain \& Thornton, 1998). The main finding from Musolino et al.'s study is that while adults can easily access the non-isomorphic interpretations of sentences like (16) and (17), 4-year-olds systematically assign such sentences an isomorphic interpretation only.

For example, one of the stories used to test children's comprehension of (16) involved three horses trying to jump over a fence. Two of the horses successfully jump over the fence but the third one doesn't. At the end of the story, a puppet describes the situation as follows: "Every horse didn't jump over the fence". Note that this statement is true on the non-isomorphic (i.e. 'not all') reading of the sentence since it is true that not all of the horses jumped over the fence. However, the puppet's statement is false on the 'none', isomorphic, reading, since two horses did jump over the fence. Musolino et al. found that in this case, adults always accepted the puppet's statement and therefore showed that they could easily access the non-isomorphic interpretation. Children, on the other hand, systematically rejected the puppet's statements. When asked to justify their answers, children typically said that the puppet was wrong because two of the horses did jump over the fence. Children, therefore, seem to only be able to access the isomorphic reading of the sentence.

To determine whether children's difficulty is linguistic or conceptual in nature, Musolino et al. used sentences like (18) as a control.

The Smurf didn't buy every orange

The example in (18) was used in the context of a story in which a Smurf had bought only one of three oranges, and therefore not all of them. Musolino et al. found that in this case, children had no difficulty accepting the puppet's statements that "the Smurf didn't buy every orange". Notice that in this case the 'not all' reading corresponds to an isomorphic interpretation, unlike the example in (16). The finding that children systematically assign examples like (16-18) isomorphic interpretations is what Musolino et al. call the 'Observation of Isomorphism'. 
The Observation of Isomorphism: (Musolino et al., 2000, p. 14)

Unlike adults, young children systematically interpret negation and quantified NPs on the basis of their position in overt syntax.

Musolino et al.'s findings raise a number of interesting questions.

First, these results do not tell us the nature of the constraint underlying children's resistance to non-isomorphic interpretations. One possibility is that children's overly isomorphic interpretations reflect the linear arrangement between the quantified NPs and negation. This wouldn't be surprising since it has been suggested in the psycholinguistic literature that for adults, linear order is one of the factors influencing the resolution of quantifier scope ambiguities on-line (Kurtzman \& MacDonald, 1993). Alternatively, children's interpretations may be constrained by the surface c-command relations holding between these elements. This would also make sense since c-command is the linguistic determinant of scope. It is unclear whether isomorphism obtains as a consequence of the linear position of the quantified NPs and negation or whether it follows from the c-command relations between these elements because these two notions are systematically confounded in the material used by Musolino et al. As can be seen in the tree diagrams below, the subject position always precedes and falls outside the c-command domain of negation while the object position always follows and falls within the c-command domain of negation.
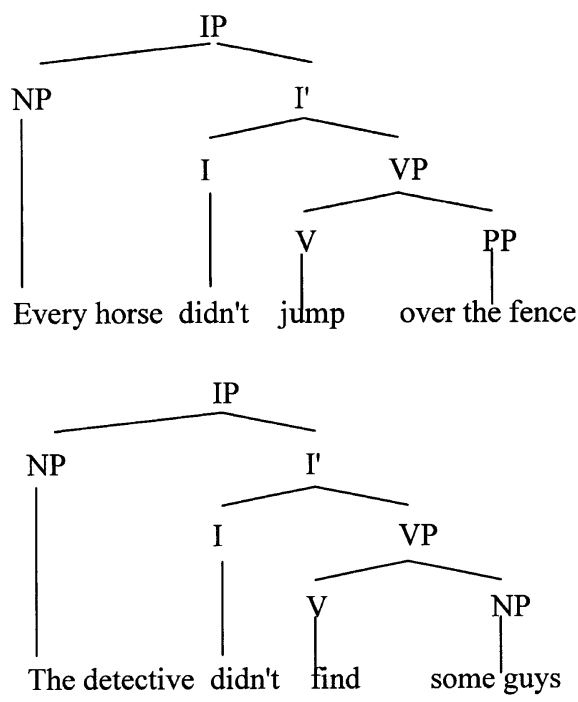

Teasing apart linear order from hierarchical structure is important because the answer to this question can give us insight into the nature of children's linguistic representations. In particular, we can find out whether the theoretical constructs of syntactic theory play an explanatory role not only in models of adult grammatical competence but also in our understanding of children's non-adult behavior. Simply put, do children's linguistic representations have the same character as those of the adults they eventually become? We will call this the structural question.

Another question raised by Musolino et al.'s findings is whether the observation of 
isomorphism in children is bound to the lexical properties of the quantified NPs tested by these authors, i.e. every $N$ and some $N$. This is what we call the lexical question. This question grows out of the observation that the availability of non-isomorphic interpretations sometimes depends in the adult grammar on the lexical nature of the quantified NPs involved. For example, the sentence The detective didn't find some guys, as we discussed earlier, seems to require a non-isomorphic interpretation (i.e. there are some guys that the detective didn't find). However, replace the NP some guys by any guys and the sentence in (19) no longer allows a non-isomorphic interpretation. That is, (19) must mean that the detective found no-one, as shown by the logical representation in (19b). Now replace any guys by one guy, as in (20), and the sentence becomes ambiguous again between an isomorphic and a non-isomorphic interpretation, as shown in (20a) and (20b), respectively.

(19) The detective didn't find any guys

a. $* \exists x[\operatorname{guy}(\mathrm{x}) \wedge \neg$ find(detective, $\mathrm{x})]$

b. $\neg \neg \mathrm{x}[\operatorname{guy}(\mathrm{x}) \wedge$ find(detective, $\mathrm{x})]$

(20) The detective didn't find one guy

a. $\quad \neg \exists x[\operatorname{guy}(\mathrm{x}) \wedge$ find(detective, $\mathrm{x})]$

b. $\quad \exists x[\operatorname{guy}(\mathrm{x}) \wedge \neg$ find(detective, $\mathrm{x})]$

A third important question, related to the scope of the phenomenon observed by Musolino et al., is whether isomorphism can be observed in the acquisition of languages other than English, provided of course that they manifest the same kind of scope ambiguities with respect to QNPs and negation. We call this the cross-linguistic question.

Finally, an important question concerns the empirical basis for the observation of isomorphism. Musolino et al. showed that children rejected statements like (16) and (17) when they were true on a non-isomorphic interpretation. The children they tested justified their negative answers by invoking the fact that the statements were false on the isomorphic interpretation. In the case of (16) for example, in a situation in which two out of three horses had jumped over a fence, children who answered 'no' to the puppet's statement that Every horse didn't jump over the fence said that the puppet was wrong because two of the horses had jumped over the fence. Musolino et al. therefore inferred from children's justifications that they were accessing isomorphic interpretations. That is, they reasoned that children's answers only made sense if they had taken (16) to mean that none of the horses had jumped over the fence.

However, Musolino et al. did not directly show that children (or adults) would accept the same statements if the isomorphic reading were true. This step would have provided a clear demonstration that sentences like (16) are indeed ambiguous for adults (who accepted them on the non-isomorphic interpretation). In addition, it would have provided a direct empirical validation of the inference made by these authors based on children's rejections of non-isomorphic interpretations. That is, since children rejected the nonisomorphic reading of sentences like (16) by invoking the fact that the isomorphic reading was false, one would predict that they should accept the same sentences when the isomorphic reading is true and the non-isomorphic reading is false. 
However, as mentioned above, every situation which satisfies the truth conditions of the isomorphic (i.e. 'none') reading also satisfies the truth conditions of the non-isomorphic (i.e. 'not all') reading. Coming back to our example, we can see that if it is true that none of the horses jumped over the fence (the isomorphic interpretation), it is also necessarily true that not all of the horses jumped over the fence (the non-isomorphic interpretation). Notice that a similar entailment pattern obtains for sentences like (17). In this case, if it is true that the detective didn't find anyone (the isomorphic interpretation) it is also true that there are some individuals that the detective didn't find (the non-isomorphic reading). These entailment patterns are shown in (21).

$$
\begin{aligned}
& \text { a. } \quad \forall \mathrm{x}[\neg \mathrm{P}(\mathrm{x})] \rightarrow \neg[\forall \mathrm{x}[\mathrm{P}(\mathrm{x})]] \quad \text { none } \rightarrow \text { not all } \\
& \text { b. } \quad \neg[\forall \mathrm{x}[\mathrm{P}(\mathrm{x})]] \rightarrow \forall \mathrm{x}[\neg \mathrm{P}(\mathrm{x})] \quad \text { not all } \rightarrow \text { none }
\end{aligned}
$$

The unfortunate consequence of these entailment patterns for experimental design is that it is impossible to directly test children's (and adults) knowledge of the isomorphic readings of sentences like (16) and (17) because scenarios in which the isomorphic reading is true and the non-isomorphic reading is false are impossible to construct (but see Musolino \& Lidz, 2002). We refer to this as the entailment problem.

In Section 4 and 5, we present a series of experiments on English and Kannada, designed to address these questions. The first experiment addresses the lexical question and the entailment problem. The second experiment addresses these questions as well as the structural and cross-linguistic questions.

\section{Experiments on English}

We tested children's and adults' interpretations of ambiguous sentences like (22) containing negation and a numerally quantified object.

The detective didn't find two guys

On one reading, given in (23a), (22) can be paraphrased as 'It is not the case that the detective found two guys'. In this case, the QNP two guys is interpreted in the scope of negation, giving rise to an Isomorphic interpretation. The other reading of (22), given in (23b), can be paraphrased as 'There are two guys that the detective didn't find'. Here, the QNP two guys takes scope over negation, giving rise to a Non-Isomorphic interpretation.

$$
\begin{aligned}
& \text { a. } \left.\neg \exists_{2} \mathrm{x}[\operatorname{guy}(\mathrm{x}) \wedge \text { find(detective, } \mathrm{x})\right] \\
& \text { b. } \left.\quad \exists_{2} \mathrm{x}[\operatorname{guy}(\mathrm{x}) \wedge \neg \text { find(detective, } \mathrm{x})\right]
\end{aligned}
$$

An important feature of sentences like (22) compared to the sentences used by Musolino et al. is that while they are scopally ambiguous, there is no entailment relation between the two scope readings. The entailment problem is solved for this kind of sentence. This 
means that it is possible to conceive of a situation in which either scope reading of (22) can be true while the other reading is false. Take for example a situation in which the narrow scope reading of (22) is true. Imagine for instance that the detective only found one out of two guys that he was looking for. In this case, the narrow scope reading of the numeral in (22) is true since it is not the case that the detective found two guys (he only found one of them). However, the wide scope reading of the quantificational NP is false because in this situation it is not true that there are two guys that the detective didn't find. In fact there is only one such person. Let us now consider a situation in which the wide scope reading of the quantificational NP in (22) is true. Suppose that the detective only found two out of four guys that he was looking for and therefore that there are two guys that he didn't find. In this case, the wide scope reading of the quantificational NP in (22) is true. This situation also falsifies the narrow scope reading of the quantificational NP in (22). According to this reading, it should not be the case that the detective found two guys. Yet in this situation, the detective found exactly two guys, falsifying the narrow scope reading of the quantificational NP. Using sentences like (22), we therefore circumvent the entailment problem discussed earlier and use materials that allow us to directly test the subject's interpretation of both isomorphic and non-isomorphic scope readings. ${ }^{6}$

One part of our research question is to determine experimentally whether our intuitions about the ambiguity of sentences like (22) can be confirmed by the judgments of adult speakers of English. Recall that the Musolino et al. experiments did not explicitly test adults' (or children's) interpretation of both of the scope readings of ambiguous sentences containing quantified NPs and negation. A second part of our research question is to refine our understanding of children's non-adult interpretations of quantificational expressions. Testing young children's interpretation of sentences like (22) provides a clear proving ground for the observation of isomorphism by addressing the lexical question. This experiment will determine whether or not the observation of isomorphism is restricted to the kinds of quantified NPs tested by Musolino et al. (2000).

\subsection{Method}

\subsubsection{Subjects}

We tested 24 English-speaking children (12 boys and 12 girls) between the ages of 3;11 and $4 ; 11$ (mean 4;4). Four subjects were replaced in the design because they were too shy or because they could not provide any justifications to their answers. The children were recruited from daycare centers at the University of Maryland and in the Philadelphia area. We chose 4-year-olds because previous studies (i.e. Musolino et al., 2000) showed that it is at that age that children give non-adult responses to ambiguous sentences containing

\footnotetext{
${ }^{6}$ Notice that solving the entailment problem is vital to making the Truth Value Judgment Task methodology work properly. The reasoning behind this method is that subjects will always assent when the experimenter says at least one thing that is true (Crain \& Thornton, 1998). In other words, the method relies on listeners giving speakers the benefit of the doubt. Hence, if anything that the speaker says is true, then subjects respond by saying that the speaker did in fact speak truthfully. Thus, when we present sentences that are true on one reading but false on another and the subjects reject the statement as false, we conclude that the subjects did not access the true reading. Experimental situations in which both readings are true do not allow us to see whether speakers have access to both readings since an assent to the truth of the statement could be due to either reading being true.
} 
quantified NPs and negation. It is also important to note that choosing the TVJT as our experimental methodology imposed limits on the age of our child subjects since the task usually proves to be too complex for children under the age of 4 . In addition to children, we also tested 24 adult native speakers of English, all undergraduate students at the University of Pennsylvania.

\subsubsection{Procedure}

We tested children's and adults' interpretations of sentences like (22) using the TVJT methodology (Crain \& Thornton, 1998; Musolino et al., 2000). The TVJT involves two experimenters. The first experimenter acts out short stories in front of the subjects using small toys and props. The second experimenter plays the role of a puppet (in this case Elmo) who watches the stories alongside the subjects. At the end of the story, the puppet makes a statement about what he thinks happened in the story. The subjects' role is to determine whether the puppet's statement is 'right', in which case the puppet gets a reward (usually a piece of candy), or whether the puppet was 'wrong' in which case he gets punished and has to do some exercise (usually some push-ups). Finally, the subjects are asked to justify their answers by explaining why they think that the puppet was right or wrong. For a more detailed description of the TVJT, see Crain and Thornton (1998).

The children were first introduced to the task as a group (during circle time) and then tested individually in a quiet room away from the class. Each child received two pretest stories (one in which the puppet's statement was true and one in which it was false) and if the child could answer those appropriately (including appropriate justifications for their answers), they would then hear seven more stories: four test stories involving sentences of type (22) and three control stories, administered in a pseudo-random order.

Adult subjects were shown a videotaped version of the stories witnessed by the children, including the pretest stories. They were given a score sheet and were instructed to indicate, for each story, whether the puppet was right or wrong. They were also asked to provide a brief justification for their answers. Adult subjects were tested either individually or in groups of up to three.

\subsubsection{Materials}

We placed subjects in an experimental situation in which both scope readings of sentences like (22) are relevant in the context of the stories. The stories were constructed in such a way as to make one of the readings true and the other false. Answers of YES or NO to the puppet's statements ${ }^{7}$ (along with appropriate justifications) were therefore taken as a measure of subjects' ability to access one reading or the other.

Two versions of each story were constructed. In the first one, the wide scope reading of the numeral in sentences like (22) was true (abbreviated, $\mathrm{Wt}$ ) and the narrow scope reading of the numeral was false (abbreviated, Nf). In the second version, the wide scope reading of the numeral was false (abbreviated, Wf) and the narrow scope reading of the numeral was true (abbreviated, $\mathrm{Nt}$ ). Recall that what we call here the narrow scope reading of the numeral (abbreviated not $>$ two) corresponds to an isomorphic interpretation, since nega-

\footnotetext{
${ }^{7}$ Answers in which the subject said that the puppet spoke truthfully are coded as YES and answers in which the subject said that the puppet made a mistake are coded as NO.
} 
tion both precedes and c-commands the numerically quantified NP, whereas the wide scope reading of the numeral (abbreviated two $>$ not) corresponds to a non-isomorphic interpretation. Thus, if subjects accept the Wf/Nt version of the puppet's statement, that would indicate that they are able to access the isomorphic interpretation; if they accept the $\mathrm{Wt} / \mathrm{Nf}$ version of the puppet's statement, that would indicate that they are capable of accessing the non-isomorphic interpretation.

In the $\mathrm{Wt} / \mathrm{Nf}$ version of the story (corresponding to the example in (22)), Donald and four of his friends are playing hide-and-seek. Donald finds two of his friends but fails to find the other two. At the end of the story, the puppet says: "I know what happened: Donald didn't find two guys, am I right?" In this case, the wide scope reading of the numeral in (22) is true because there are indeed two guys that Donald didn't find. On the other hand, the narrow scope (isomorphic) reading of the numeral, asserting that it is not the case that Donald found two guys, is false since Donald found exactly two guys. In this case therefore, a YES response (along with appropriate justification) indicates a preference for the wide scope interpretation while a NO response (along with appropriate justification) indicates a preference for the narrow scope reading. Fig. 1, which corresponds to the scene at the end of one of the stories we used, illustrates this condition.

In the $\mathrm{Wf} / \mathrm{Nt}$ version, Donald is playing hide and seek with two of his friends. He finds one of them but fails to find the other. At the end of the story, therefore, the wide scope reading of the numeral is false because it is not true that there are two guys that Donald didn't find. In fact there is only one such person. On the other hand, the narrow scope

\section{Reading 1: It is not the case that Donald found two guys (not $>$ two) $=$ FALSE}

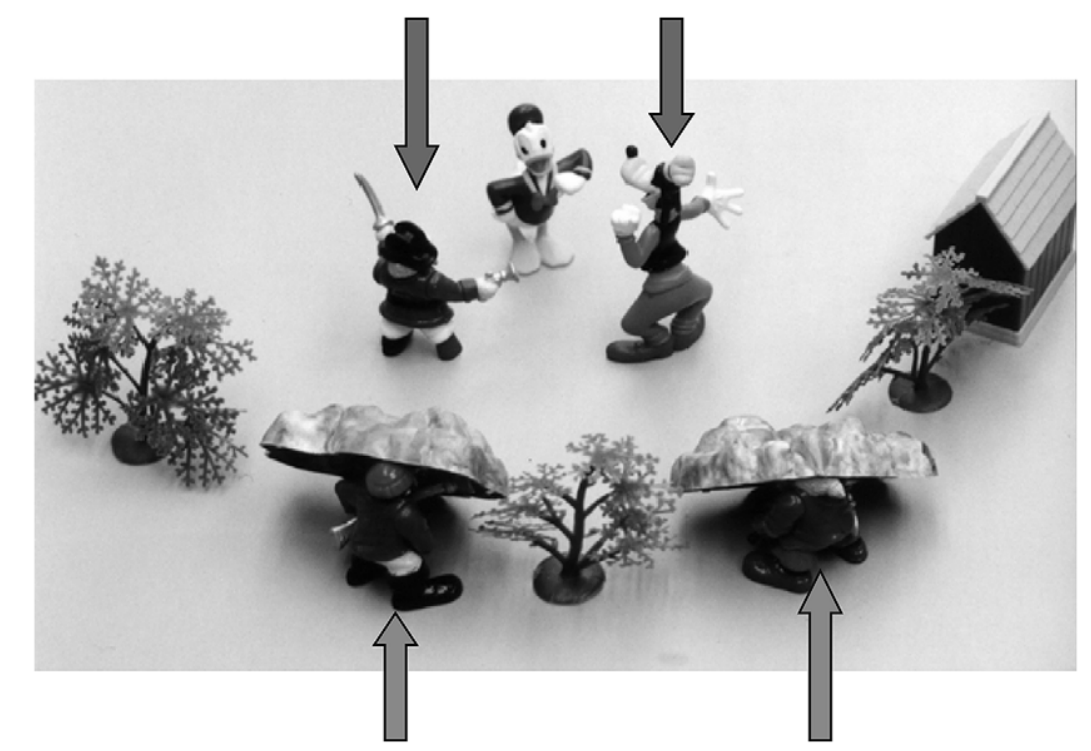

Reading 2: There are two guys that Donald didn't find (two $>$ not) $=$ TRUE

Fig. 1. 'Donald didn't find two guys', WtNf Condition. 
Reading 1: It is not the case that Donald found two guys (not $>$ two) $=$ TRUE

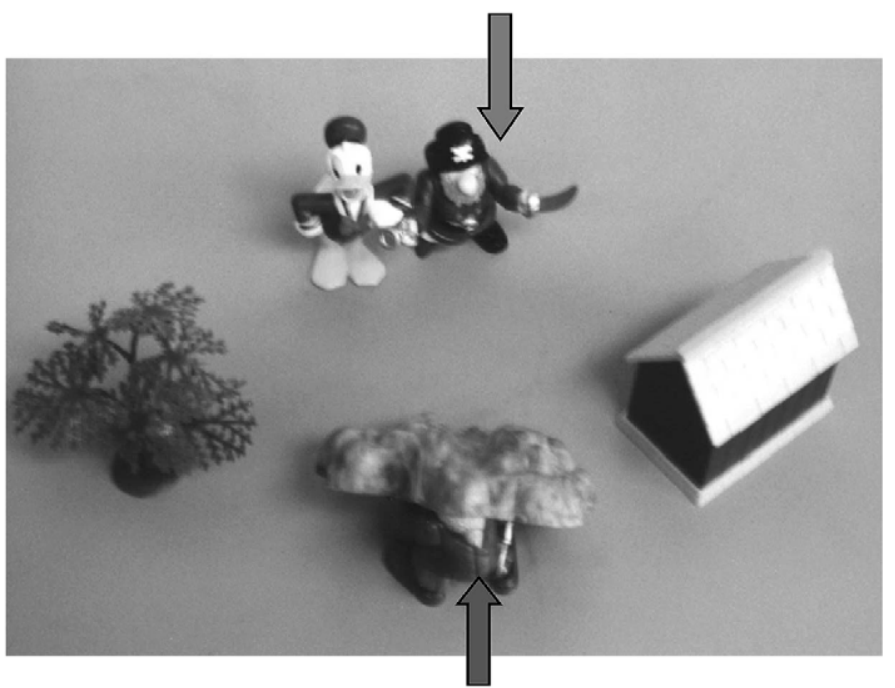

\section{Reading 2: There are two guys that Donald didn't find (two $>$ not) $=$ FALSE}

Fig. 2. 'Donald didn't find two guys', WfNt Condition.

reading of the numeral is true because it is indeed not the case that Donald found two guys. He only found one. Fig. 2 illustrates this condition.

The statements made by the puppet on each of the four test trials are given in Table 1 (see Appendix A for the plot). When making these statements, the experimenter holding the puppet was instructed to say the sentences in a way that is the most naturally compatible with the appropriate reading on which the sentence was a true description of what had happened in the story. This step was taken to ensure that if there are any prosodic cues associated with the different scope readings, they would be provided to the child subjects by the experimenter holding the puppet.

In addition to the four test stories, each subject also witnessed three control stories. Unlike the test items, the statements made by the puppet on the control stories were not ambiguous. The purpose of these stories was to control for children's knowledge of the meaning of the separate linguistic elements involved in the scope ambiguities discussed above, i.e. negation and NPs of the form two $N$. The experimenter holding the puppet had a choice between two different statements for each of the control stories. One statement was

Table 1

Puppet's statements on test stories for both Wt/Nf and Wf/Nt conditions

\begin{tabular}{ll}
\hline Test story 1 & 'Cookie Monster didn't eat two slices of pizza' \\
Test story 2 & 'The caveman didn't ride two horses' \\
Test story 3 & 'Donald didn't find two guys' \\
Test story 4 & 'The boy didn't pet two animals'
\end{tabular}


true in the context of the story and the other was false. If the child had answered YES to a given test story, the experimenter holding the puppet was instructed to pick the statement for the following control story corresponding to a NO answer, and vice-versa. This ensured that the number of YES and NO answers was balanced. Another precaution that was taken to ensure that children knew the meaning of two was to have each subject count the number of toys or characters in each of the stories as they were being laid out on the table. The list of statements made by the puppet on the control stories is given in Tables 2 and 3 for each of the two conditions.

Finally, the 48 subjects ( 24 adults and 24 children) were randomly assigned to each condition (i.e. WtNf and $\mathrm{WfNt}$ ) thus giving rise to the following $2 \times 2$ design with scope condition and age as between subject factors and 12 subjects per cell (Table 4 ). The group of 12 children assigned to the WtNf condition ranged in age between $3 ; 11$ and $4 ; 11$ (mean 4;4, median $4 ; 4$ ) and the range for the group assigned to the WfNt condition was $4 ; 1$ to $4 ; 9$ (mean $4 ; 5$, median $4 ; 5)$. The mean ages for these two groups do not differ significantly $(P=0.46)$.

Since the puppet's statements on critical trials are ambiguous, we chose to treat scope condition (i.e. WtNf and $\mathrm{WfNt}$ ) as a between subject factor, instead of a within subject factor, in order to avoid potential contaminating effects between the two possible readings. That is, once children become aware of one of the possible interpretations for the ambiguous statements, they may find it difficult to later assign a similar statement a different interpretation. In other words, the initial interpretation that children assign to statements of the form NP didn't $V$ two $N$ may influence the way they interpret subsequent statements of the same form. ${ }^{8}$

\subsection{Results}

In the analysis below, our dependent measure was the proportion of YES responses to the puppet's statements. Beginning with subjects' responses to the test items (Fig. 3), we found no significant difference in adult's acceptance rates in the WtNf and WfNt conditions (93 and 97\%, respectively). However, we found that children accepted the puppet's statements reliably more often in the WfNt condition, as compared to the WtNf condition (81 vs. $33 \%$, respectively, $t(22)=3.62, P=0.001) .{ }^{9}$ The proportions of YES responses

\footnotetext{
${ }^{8}$ One way to avoid this problem in a within subject design is to use a 'block design' in which subjects are presented with all statements of one kind, say WtNf, followed by all statements of the other kind, i.e. WfNt. By counterbalancing order of presentation (half of the subjects hear WtNf statements first and the other half hears WfNt first) one can control for the existence of the kind of effects mentioned above.

${ }^{9}$ On the assumption that chance performance on this task corresponds to a 50\% acceptance rate, children's performance in the WtNf condition (i.e. 33\% acceptance rate) did not significantly differ from chance $(P=0.16)$. In the WfNt condition children's acceptance rate, i.e. $81 \%$, was significantly above what would be expected by chance $(P<0.001)$. However, these estimates should be treated with caution as it is unclear what chance performance on this task would actually correspond to. In order to get a more accurate estimate, one would need to quantify potential biases that children may display in favor of one kind of response or another. For example, children who are confused may generally opt for a YES answer, thus giving rise to a well-known YES bias (see Crain \& Thornton, 1998). In such a case, we would also expect children not to be able to provide adequate justifications for their responses. Notice that this is not what we found here. Whether they accepted or rejected the puppet statements, children consistently provided appropriate justifications. Finally, note that the experiments presented here were not designed to assess children's behavior against expected chance behavior but rather to compare their behavior in different experimental conditions (i.e. WtNf, WfNt).
} 
Table 2

Puppet's statements on control stories, WfNt condition

\begin{tabular}{|c|c|}
\hline Control 1 & $\begin{array}{l}\text { 'Donald didn't find all the rings' (FALSE) } \\
\text { 'Donald found all the rings' (TRUE) }\end{array}$ \\
\hline Control 2 & $\begin{array}{l}\text { 'Minnie didn't buy any of the balloons' (FALSE) } \\
\text { 'Minnie only bought two of the balloons' (TRUE) }\end{array}$ \\
\hline Control 3 & $\begin{array}{l}\text { 'Smurfette didn't buy the bird' (FALSE) } \\
\text { 'Smurfette bought a bird and a cat' (TRUE) }\end{array}$ \\
\hline
\end{tabular}

were entered into an analysis of variance (ANOVA) with two factors: age (adults, 4-yearolds) and condition (WtNf, WfNt). The analysis revealed a main effect of age $(F(1,44)=27.23, \quad P<0.0001), \quad$ a main effect of condition $(F(1,44)=12.43$, $P<0.001)$ and a reliable interaction between age and condition $(F(1,44)=8.77$, $P<0.01)$.

On the control items, children gave correct answers $97 \%$ of the time in the WfNt condition and $94 \%$ of the time in the WtNf condition (recall that the puppet's statements in this case were not ambiguous). Adults gave correct answers to the control items 100\% of the time, in both conditions (Fig. 4). An ANOVA with two factors, age and condition, was performed on the proportion of correct responses to control items. We found no reliable effect of age $(F(1,44)=1.8, P=0.18)$, no reliable effect of condition $(F(1,44)=0.19, \quad P=0.66)$ and no interaction between age and condition $(F(1,44)=0.19, P=0.66)$.

In the WtNf condition, in which two objects/characters were eaten/ridden/found/petted by the main character and two were not, children rejected the puppet's statements, i.e. sentences of the form 'NP didn't V two N', 66\% of the time (i.e. on 32 out of 48 trials). When asked why the puppet was wrong, children typically answered that the main character did indeed ride/eat/find/pet two of the objects/characters. Fig. 5 shows some examples of children's justifications.

Responses of this type, making direct reference to the fact that the character in question had indeed ridden/eaten/found/petted two of the objects or other characters, accounted for $90 \%$ of children's negative responses. That is, children almost always rejected the puppet's statements invoking the isomorphic interpretation of the target sentences.

In the WfNt condition, in which one object/character was eaten/ridden/found/petted by the main character and one was not, children accepted the puppet's statements, that is, sentences of the form 'NP didn't V two N', 81\% of the time (i.e. on 39 out of 48 trials). When asked why the puppet was right, children typically answered that the puppet was

Table 3

Puppet's statements on control stories, WtNf condition

\begin{tabular}{ll}
\hline Control 1 & 'The old man hurt two guys' (TRUE) \\
'The old man didn't hurt any of the guys' (FALSE) \\
Control 2 & 'The troll only bought one pumpkin' (TRUE) \\
& 'The troll bought all the pumpkins' (FALSE) \\
Control 3 & 'The cheetah only ate the hotdog' (TRUE) \\
& 'The cheetah ate all the food' (FALSE)
\end{tabular}


Table 4

\begin{tabular}{lll}
\hline & Wide True/Narrow False & Wide False/Narrow True \\
\hline 4-year-olds $(n)$ & 12 & 12 \\
Adults $(n)$ & 12 & 12 \\
\hline
\end{tabular}

right because the main character only ate/rode/found/petted one of the objects/characters. Fig. 6 shows some examples of children's justifications.

Responses of this kind, making direct reference to the fact that the main character had performed the relevant action with respect to only one of the objects/characters, accounted for $91 \%$ of children's justifications. This clearly shows that children correctly accepted the puppet's statements because the isomorphic reading of the test sentences was true, i.e. it was not the case that the main character ate/rode/found/petted two objects/characters.

Adults always gave appropriate justifications to the puppet's statements, in both conditions.

\subsection{Discussion}

The results presented above show that our intuitions about the scope ambiguities in sentences like Donald didn't find two guys are correct. Adult speakers of English can easily assign either scope interpretation, as indicated by the proportions of YES responses in each condition (93\% for $\mathrm{WtNf}$ and $97 \%$ for $\mathrm{WfNt}$ ). These results also underscore an important property of the TVJT, namely the fact that subjects seem to prefer to give the puppet credit for speaking truthfully, if that is possible. Notice that this could in principle have been otherwise since the statements that subjects were asked to evaluate in each condition could have legitimately been interpreted as either true or false, depending on which scope reading one judges to be relevant (see Crain \& Thornton, 1998 for further

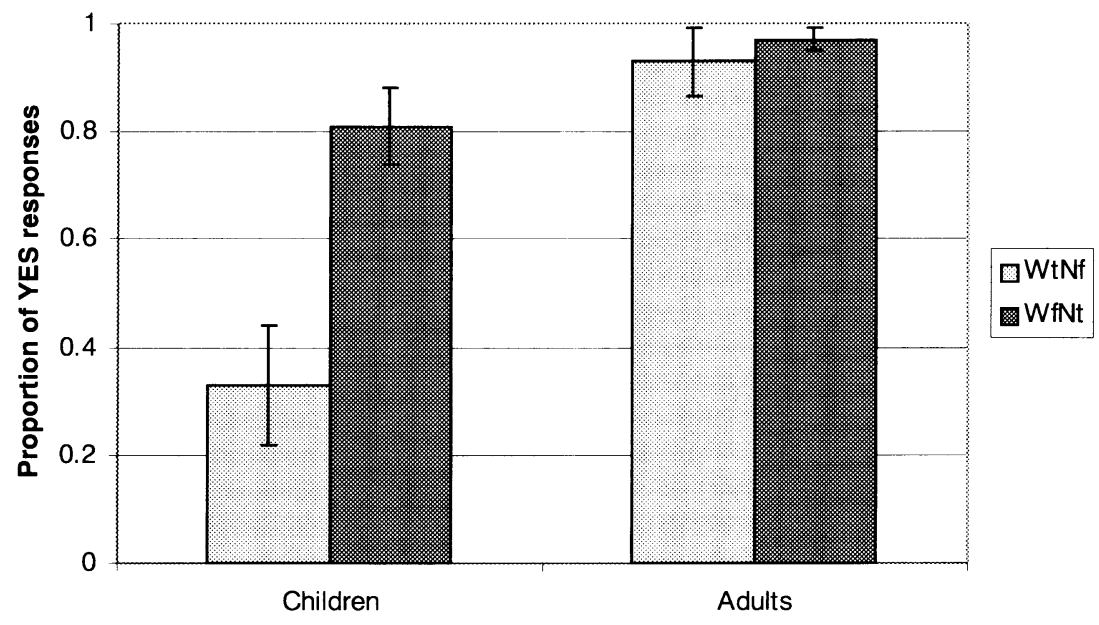

Fig. 3. Proportion of YES responses to test trials for children and adults in each of the two conditions. 


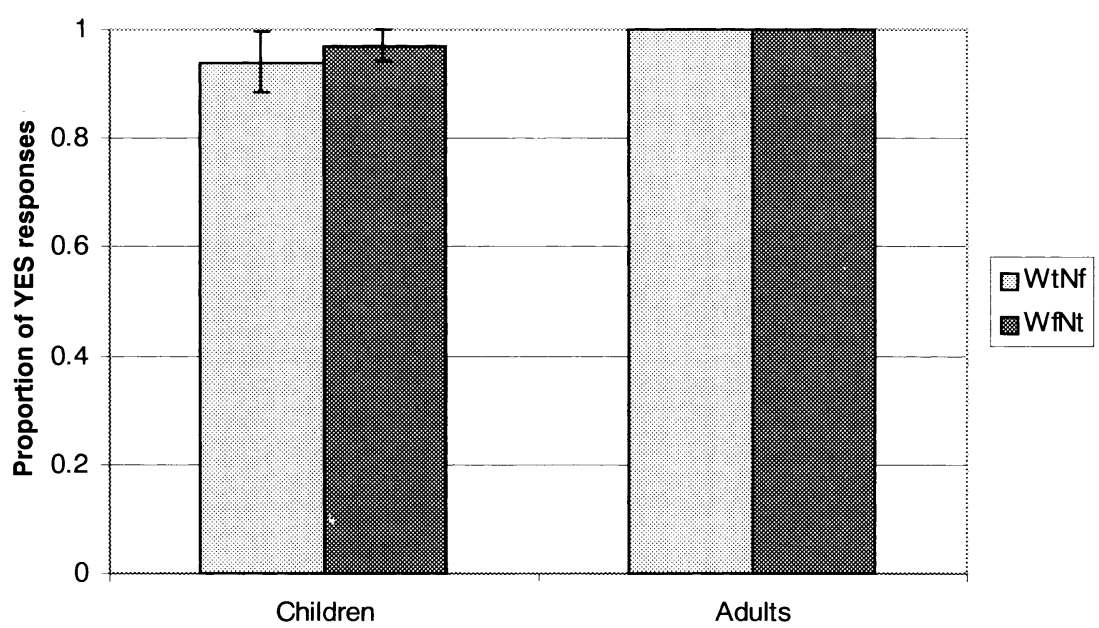

Fig. 4. Proportion of correct responses to control trials for children and adults in each of the two conditions.

discussion). Second, children's almost perfect performance on control stories (i.e. 95\% correct answers on average) indicates that they didn't experience any difficulty with the task. More importantly, this shows that neither negation, nor quantified NPs of the type two $N$, when considered separately, posed any problems to children. This also shows that

\section{Puppet:"Donald didn't find two guys"}

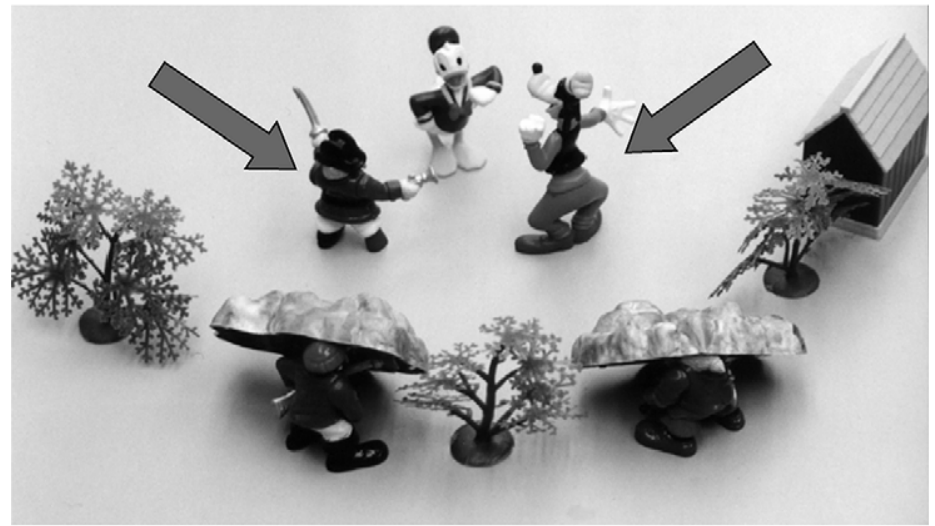

Child (pointing to the two guys Donald found):

He did! or

He did find two guys! or

You're wrong, he did! He found two guys!

Fig. 5. 
Puppet: "Donald didn't find two guys"

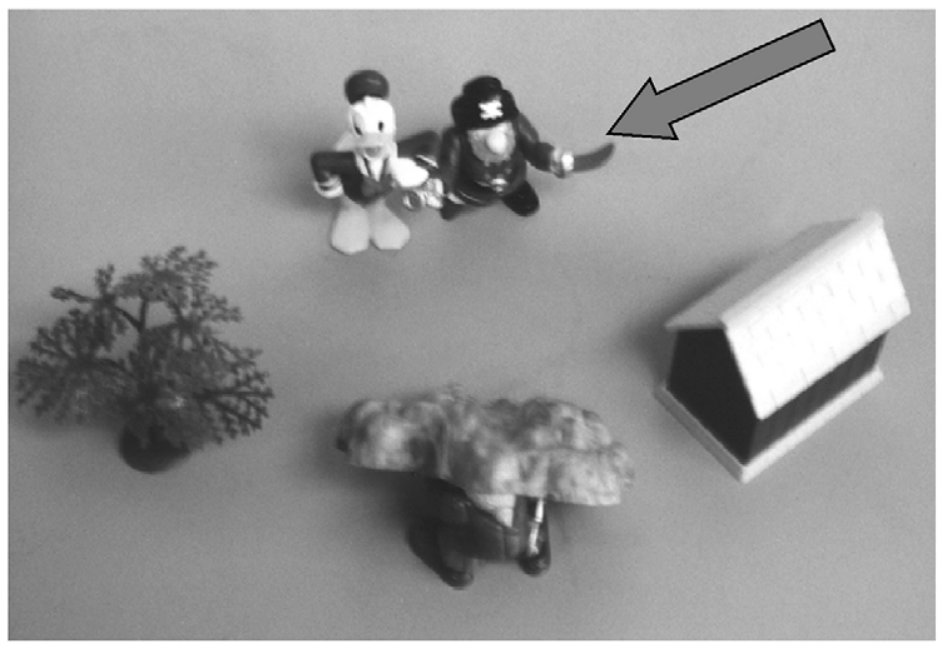

Child (pointing to the only guy that Donald found):

"You re right because he only found one." or "You're right. He found one. He didn't find two."

Fig. 6.

children were able to say YES and NO when appropriate since the control stories were designed to evoke both types of answer.

Finally, these results strengthen the findings of Musolino et al. (2000) by showing with numerally quantified NPs that 4-year-olds have a reliable preference for the narrow scope, isomorphic reading of quantified objects (i.e. 81 vs. $33 \%$ acceptance rate, respectively, $P<0.001$, along with appropriate justifications).

The observation of isomorphism, now extended to children's interpretation of negation and numerally quantified NPs, leaves open a number of important questions. As always, when differences in the linguistic behavior of children and adults are uncovered, one needs to try to explain what factors, linguistic or other, give rise to such differences.

Our observation also raises a question discussed at length in the psycholinguistic literature on ambiguity resolution (Kurtzman \& MacDonald, 1993; others). When the rules of grammar allow more than one interpretation to be assigned to a sentence, it is standard practice for psycholinguists to regard preferences for one interpretation or the other as arising from the operation of comprehension/processing principles (Frazier \& Fodor, 1978). In the case of quantifier scope ambiguities two main principles have been invoked to explain such preferences. The first is based on the notion of linear order. According to this principle, the preferred scope reading for quantified phrases corresponds to the left-toright ordering of the phrases in the surface form of the sentence (Bunt, 1985; Fodor, 1982; Johnson-Laird, 1969; Kroch, 1974; among others). The other principle relies on the hierarchical relations between the constituents of a sentence. One version of this principle, 
for example, seeks to account for scope preferences in terms of the c-command relation between the quantified phrases (May, 1985; Reinhart, 1983; also see Frazier, 2000; Kurtzman \& MacDonald, 1993 for discussion of this principle). Although a good deal is known about the parsing mechanisms used by adult speakers to resolve ambiguous sentences (see Tanenhaus \& Trueswell, 1995), this question has only rarely been investigated in the case of children (but see Crain \& Thornton, 1998; Trueswell, Sekerina, Hill, \& Logrip, 1999).

Our results so far suggest that children's interpretation of ambiguous sentences containing negation and quantified NPs is constrained by the position of these elements in the surface string. However, as we have noted, it is unclear at this point whether isomorphism obtains as a result of a constraint imposed by the linear order between negation and the quantified NP or by the more abstract notion of c-command defined over the hierarchical relations between these elements. This is because in the examples that we have tested so far, the two notions are confounded (this is also true of the examples used by Musolino et al., 2000). As can be seen in (24), the quantified object falls within the c-command domain of negation. Hierarchical relations therefore map to a narrow scope reading. The quantified object also follows negation. The linear relation between negation and the object QNP therefore also maps to a narrow scope interpretation. Both notions are therefore compatible with children's interpretations.

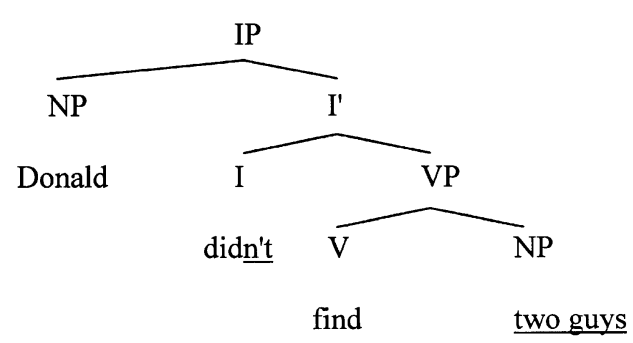

Finally, we return to the cross-linguistic question. Is the observation of isomorphism an observation about the acquisition of quantificational structure in English alone or is it a more widespread property that can be observed in children's acquisition of quantificational structure in other languages as well? In Section 5, we present the results of an experiment on child and adult speakers of Kannada, a Dravidian language which offers the advantage of allowing us to simultaneously address the cross-linguistic and the structural questions. We discuss the questions regarding the possible causes of children's difficulty with non-isomorphic interpretations and the transition to the adult system of interpretation in Section 6.

\section{Experiments on Kannada}

\subsection{Scope ambiguities and the structure of Kannada}

Kannada is a Dravidian language spoken by approximately 40 million people in the state of Karnataka in south-western India. The canonical word order in Kannada is Subject-Object-Verb (SOV) and Kannada displays the same kind of scope ambiguities 
as English with respect to negation and quantified NPs (Lidz, 1999). These properties are illustrated in (25), which can be interpreted as meaning that it is not the case that I read two books, a narrow scope interpretation of the numeral, or that there are two books that I didn't read, a wide scope interpretation of the numeral.

$$
\begin{array}{lll}
\text { naanu eraDu pustaka } & \text { ood-al-illa } \\
\text { I-nom two book } & \text { read-inf-neg } \\
\text { 'I didn't read two books' } &
\end{array}
$$

The crucial difference between Kannada and English for our purposes is that in Kannada, linear order and c-command relations are not confounded. Consider the tree diagrams given in (26). In English, negation both precedes and c-commands the object position, as discussed earlier. In Kannada, however, negation c-commands the object but does NOT precede it. This means that in Kannada, a c-command account of isomorphism would predict a narrow scope reading of the object with respect to negation whereas a linear account of isomorphism would predict a wide scope reading of the object (Table 5).

$\underline{\text { Kannada }}$

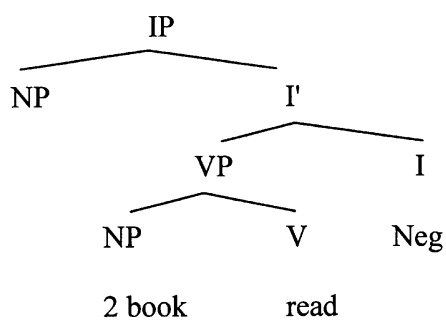

English

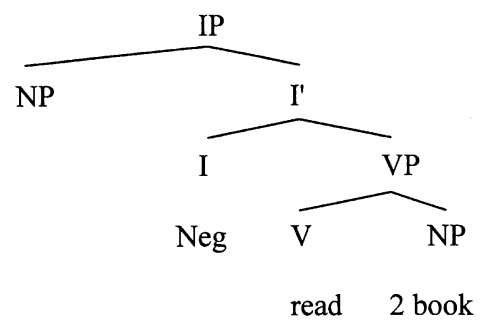

Kannada therefore provides the ideal paradigm to tease apart the contribution of linear and hierarchical relations in children's interpretation of scope relations. To the extent that Kannada-speaking children are restricted to one of the two possible interpretations of sentences like (25) in the way that English-speaking children are, linear order and hierarchical relations make opposite predictions:

Linear prediction

If children's interpretations of scope relations are constrained by linear order, then

Table 5

Predictions of the two accounts of isomorphism

\begin{tabular}{lll}
\hline & Kannada & English \\
\hline C-command & Narrow scope reading of object NP & Narrow scope reading of object NP \\
Precedence & Wide scope reading of object NP & Narrow scope reading of object NP \\
\hline
\end{tabular}


children will display a preference for the wide scope reading of the object with respect to negation.

Hierarchical prediction

If children's interpretations of scope relations are constrained by c-command relations between negation and the quantified object, then children will display a preference for the narrow scope reading of the object with respect to negation.

\subsection{Method}

\subsubsection{Subjects}

In order to test native speakers of Kannada, we went to Mysore, India where we tested 24 Kannada-speaking 4-year-olds (11 girls and 13 boys) between the ages of 4;0 and 4;11 (mean 4;5) from Pushkarini and Swami Vivekanada preschools and 24 Kannada-speaking adults from Mysore University. An additional six children were tested but eliminated from the study either because they always gave the same answer or because they could not justify their answers.

\subsubsection{Procedure}

As in the experiment on English, speakers of Kannada were tested using the TVJT methodology. Both experimenters - the one telling the stories and the one playing the part of the puppet - were native speakers of Kannada. Unlike their English counterparts, Kannada-speaking adults did not see a videotaped version of the stories. Instead, the stories witnessed by Kannada-speaking adults were also acted out in front of them. Subjects received a pretest consisting of two stories followed by a series of seven stories (four test stories and three filler stories) administered in a pseudo-random order. The 48 subjects ( 24 adults and 24 children) were randomly assigned to each of the two conditions (i.e. WtNf and $\mathrm{WfNt}$ ) giving rise to the same $2 \times 2$ design used in the experiment on English. The children were tested individually in a quiet area outside the classroom. The adults were tested individually or in groups of up to ten.

\subsubsection{Materials}

As before, two versions of the stories were constructed. In one version, the wide scope reading of the numeral was true (abbreviated, $\mathrm{Wt}$ ) and the narrow scope reading was false (abbreviated, Nf). To accomplish this, the stories typically involved a main character and four objects on which an action was to be performed. In the stories, the character performed the action on two of the four objects but not on the other two. In the end therefore, a statement like $N P$ didn't $V$ two $N$ was true on a wide scope interpretation of the numeral since there were two objects on which the action hadn't been performed. On the other hand, the narrow scope reading of the numeral was false because the number of objects on which the action had been performed was exactly two.

In the other version of the stories, the wide scope reading of the numeral was false (abbreviated, Wf) and the narrow scope reading was true (abbreviated, Nt). This was achieved by having the main character attempt to perform the action with respect to 
Table 6

Puppet's statements on test stories for both $\mathrm{Wt} / \mathrm{Nf}$ and WF/Nt conditions

\begin{tabular}{ll}
\hline Test story 1 & $\begin{array}{l}\text { Anoop eradu kaaru toley-al-illa } \\
\text { 'Anoop didn't wash two cars' }\end{array}$ \\
Test story 2 & $\begin{array}{l}\text { Avanu eradu biskit tinn-al-illa } \\
\text { 'He didn't eat two cookies' }\end{array}$ \\
Test story 3 & $\begin{array}{l}\text { Rashmi kekku-ge eradu moTTe hak-al-illa } \\
\text { Test story } 4\end{array}$ \\
& 'Rashmi didn't put two eggs into the bowl' \\
& Huduganu eradu ungra karedis-al-illa \\
\hline
\end{tabular}

two objects instead of four. In the stories, the character would perform the action on one of the objects but not on the second one. At the end of the stories, therefore, the wide scope reading of sentences like $N P$ didn't $V$ two $N$ was false since the character failed to perform the action with respect to only one of the objects. On the other hand, the narrow scope reading was true because it was indeed not the case that the character performed the action with respect to two objects. The statements made by the puppet on each of the four test trials in both conditions are given in Table 6 . The list of statements made by the puppet on control stories is given in Table 7.

\subsection{Results}

As before, our dependent measure was the proportion of YES responses to the puppet's statements. Beginning with subjects' responses to test items, we found that Kannada-speaking adults gave YES responses to the wide scope reading $87.5 \%$ of the time in the WtNf condition and that they gave YES response to the narrow scope reading $85.4 \%$ of the time in the WfNt condition. No significant differences were found between these two acceptance rates. However, we found that 4-year-olds accepted the puppet's statements reliably more often in the WfNt condition than in the WtNf condition (i.e.

Table 7

Puppet's statements on control stories

\begin{tabular}{lll}
\hline Control story 1 & $\begin{array}{l}\text { Simha muru haavu hiD-i-tu } \\
\text { 'The lion found three snakes' } \\
\text { Simha eradu haavu hiD-i-tu } \\
\text { 'The lion found two snakes' } \\
\text { Ha manushya ella baNDe ett-id-a } \\
\text { 'That man lifted all the rocks' } \\
\text { Ha manushya eradu baNDe ett-id-a } \\
\text { 'That man lifted two rocks' } \\
\text { Ella kappe maney-a meele haar-i-tu } \\
\text { 'All the frogs jumped over the house' } \\
\text { Eradu kappe maney-a meele haar-i-tu } \\
\text { 'Two frogs jumped over the house' }\end{array}$ \\
\hline
\end{tabular}




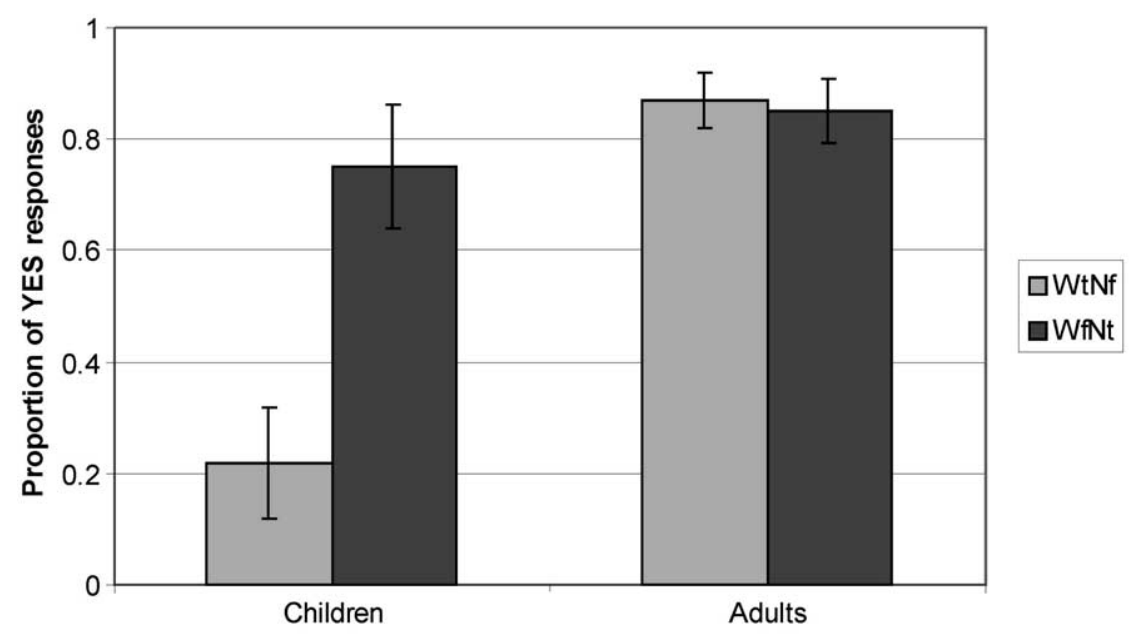

Fig. 7. Proportion of YES responses to test trials for children and adults in each of the two conditions.

$75 \%$ of the time vs. $22.9 \%$ of the time, $t(22)=3.49, P=0.002) .{ }^{10}$ The proportions of YES responses to the puppet's statements were entered into an ANOVA with two factors: age (adults, 4-year-olds) and condition (WtNf, WfNt). The analysis revealed a main effect of age $(F(1,44)=20.19, P<0.0001)$, a main effect of condition $(F(1,44)=8.97, P<0.01)$ and a reliable interaction between age and condition $(F(1,44)=10.53, P<0.01)$ (Fig. 7).

On control items, we found that adults gave correct answers $94 \%$ of the time in both conditions. Children gave correct responses to control items $97 \%$ of the time in the $\mathrm{WtNf}$ condition and $100 \%$ of the time in the WfNt condition. The proportions of correct responses to control items were entered into a ANOVA with two factors, age and condition, and we found no reliable effect of age $(F(1,44)=1.94, P=0.17)$, no reliable effect of condition $(F(1,44)=0.21, P=0.64)$ and no reliable interaction between age and condition $(F(1,44)=0.21, P=0.64)$ (Fig. 8$)$.

Finally, the justifications given by the Kannada children and adults in each of the two conditions matched those reported for English. That is, in the WtNf condition, children rejected the puppet statements by invoking the fact that the main character had indeed performed the relevant action with respect to two objects/characters. In the WfNt condition, they accepted the puppet statements and correctly pointed out that the main character had only performed the relevant action with respect to one of the objects/characters (Figs. 5 and 6).

\footnotetext{
${ }^{10}$ Since we did so for English, we compare here children's performance on each of the two critical conditions to chance performance. Of course, these estimates deserve the same qualifications as the ones discussed in the case of English-speaking children. We found that Kannada-speaking children's acceptance rate in the WtNf condition, i.e. $22.9 \%$, was reliably lower than what would be expected by chance $(P=0.01)$, suggesting that children were reliably selecting the narrow scope interpretation. Similarly, in the WfNt condition, children's acceptance rate, i.e. $75 \%$, was significantly above what would be expected by chance $(P<0.05)$, suggesting that children were reliably selecting the narrow scope interpretation.
} 


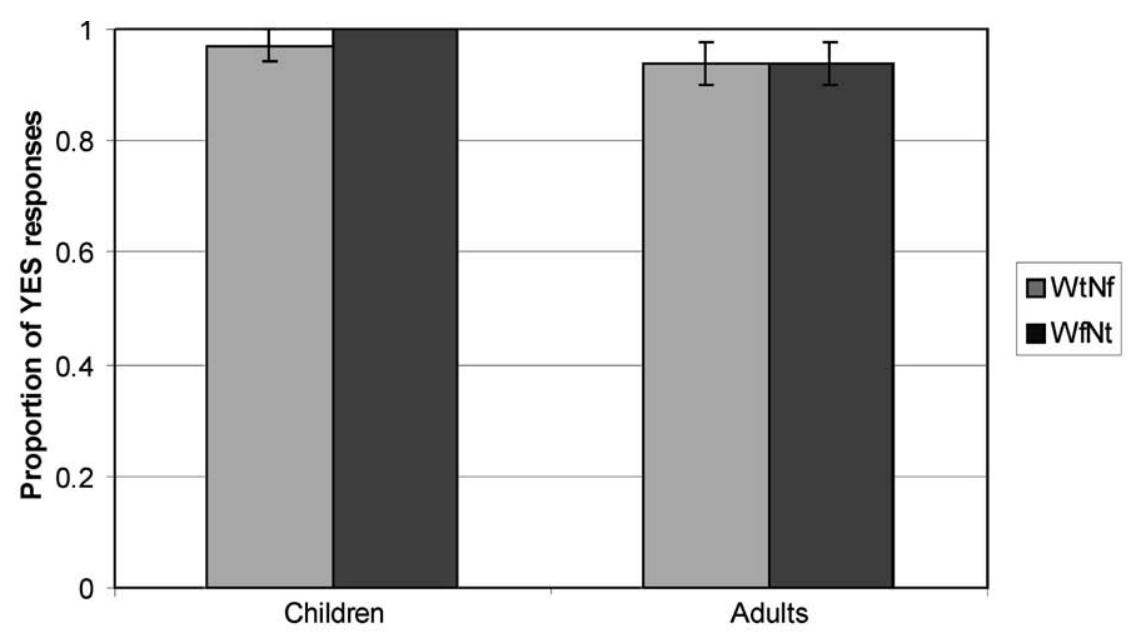

Fig. 8. Proportion of correct responses to control trials for children and adults in each of the two conditions.

\subsection{Discussion}

Our results on Kannada confirm the fact that sentences containing negation and numerally quantified objects are ambiguous in that language too, as witnessed by the fact that adult speakers of Kannada can easily assign either scope interpretation to these sentences (i.e. $87.5 \%$ acceptance rate in the WtNf condition and $85.4 \%$ in the WfNt condition). For children, the results on Kannada also replicate the pattern observed for English, namely the fact that children, unlike adults, display a reliable preference for one of the two scope readings. In that regard, recall the predictions that were made previously regarding Kannada-speaking children's interpretation of such ambiguous sentences.

\section{Linear prediction}

If children's interpretations of scope relations are constrained by linear order, then children will display a preference for the wide scope reading of the object with respect to negation.

\section{Hierarchical prediction}

If children's interpretations of scope relations are constrained by c-command relations between negation and the quantified object, then children will display a preference for the narrow scope reading of the object with respect to negation.

Our results show that children have a reliable preference for the narrow scope reading of the quantified objects with respect to negation in favor of the wide scope reading (i.e. $75 \mathrm{vs.}$ $22.9 \%$ acceptance rate, respectively). We conclude that the Isomorphism effect is a consequence of hierarchical structure rather than linear order. Children's interpretations of scope relations are limited in a way that falls out directly from building syntactic structure, since in the surface syntax, negation c-commands the quantificational expression. Although precedence relations can be determined directly from the speech signal, children do not use these 
relations in computing semantic scope. Rather, the syntactic structure imposed by a speaker on the speech signal determines the scope of quantificational elements.

\section{General discussion}

Let us summarize our findings. In the experiments presented here, we asked how speakers of English and Kannada resolve scope ambiguities involving the interaction of negation and numerally quantified object NPs. Our main finding is that in both languages adults readily assign either interpretation, whereas 4-year-olds display a strong preference for the narrow scope reading of the object. Thus, regardless of language, children's preferences are characterized by an over-reliance on the surface properties of linguistic structures. This result extends the Musolino et al. (2000) Observation of Isomorphism to the case of numerally quantified NPs. More importantly though, our results on Kannada show that children compute scope relations on the basis of the surface c-command relations between negation and the object, not on the basis of linear order. This demonstrates that young children, like adults, represent sentences as hierarchical constructs and not mere strings of words, lending support, in children, to one of the fundamental discoveries of modern linguistics. Where children differ from adults is in their readiness to apply the covert displacement operations discussed at the outset of this paper. That is, children take the surface syntactic representation to encode the same hierarchical relations as the semantic representation.

Returning to a question that was raised earlier, we may now ask why children differ from adults in the way that we observed. In other words, why do children initially fail to assign a wide scope interpretation to quantified objects? As always in such cases, two types of explanation are possible. The first one is that until a certain stage in grammatical development, children do not have implicit knowledge of the fact that such interpretations can be generated by the grammar of their language. This kind of account is usually known as a 'competence' or 'grammatical' account in the linguistic literature (Chomsky, 1965, 1986). On such an account, children reject non-isomorphic interpretations because their grammars do not include the covert displacement operation (see discussion in Section 2) that is required to generate these readings. Krämer (2000) proposes a semantic account along these lines on the basis of results from Dutch-speaking children. Specifically, she suggests that these children may initially lack knowledge of the fact that indefinite NPs can receive what she calls a free variable interpretation, which is equivalent to what we have been calling a wide scope interpretation. This, in essence, amounts to the claim that children lack knowledge of one of the grammatical operations responsible for the interpretation of indefinite NPs.

Another possibility is that child interpretations result from some limitation on the computational resources that children deploy during language comprehension. That is, although children's grammars may generate both possible readings, they may not be able to access the non-isomorphic interpretations because they are computationally too taxing (see Frazier, 2000 for a specific implementation of this view). On this view, often referred to as a 'performance' or 'processing' account in the linguistic literature (Grodzinsky \& Reinhart, 1993), the child and the adult are assumed to share the same underlying grammatical knowledge but to differ in the way they implement that knowledge in the time- 
course of language comprehension. One possibility suggested by recent findings on children's ability to resolve ambiguities on-line is that children may experience a garden-path effect from which they cannot recover (Trueswell et al., 1999). In the case at hand, children may initially access the isomorphic reading and end up being stuck with it for lack of the ability to revise that initial interpretation. This view makes the interesting prediction that although adults are capable of accessing either interpretation, they may nevertheless experience a measurable garden-path effect in processing sentences with nonisomorphic readings, albeit one from which they can quickly recover. An interesting way to test this prediction would be to present adults with contexts in which both scope readings are true and examine the justifications for their necessarily positive answers. We will undertake this task in future research.

Although the data presented here do not allow us to distinguish between a competence or a performance account, it is worth mentioning that in an attempt to tease apart the two views, we presented children with a context designed to enhance the availability of the wide scope reading of sentences like 'The Smurf didn't catch two birds' (Musolino \& Lidz, 2002). In order to achieve this, we presented children with a story in which a Smurf was trying to catch three cats and four birds. In the end, the Smurf manages to catch all the cats but only catches two of the four birds. The puppet's statement in this case was "The Smurf caught all the cats but he didn't catch two birds". We tested ten 4-year-olds on this condition, using the same method as described earlier and found that children still rejected the puppet's statement $75 \%$ of the time. Note that in a similar attempt, Musolino (in press) compared children's performance on their comprehension of sentences like "Every horse jumped over the fence" vs. "Every horse jumped over the log but every horse didn't jump over the fence". Although previous work had demonstrated that children never allow a wide scope reading of negation over the universally quantified subject in sentences like "Every horse didn't jump over the fence", their performance dramatically improved when the sentence was introduced with an overt contrast. In sum, contextual factors do allow us to see that a performance account of children's reliance on isomorphic readings in sentences involving negation and a universally quantified subject NP is likely to be correct. However, these same factors were unable to shift children's preferences in sentences with a numerally quantified object NP. Further investigation is therefore required to determine whether isomorphism effects are due to performance or competence factors across the board.

Another question raised earlier in the discussion is how children eventually manage to converge on the adult system of interpretation. The answer to this question depends on how we answer the previous question regarding the nature of children's difficulty with nonisomorphic interpretations. Suppose for the sake of argument that we are dealing with a competence problem and that children's grammars are initially incapable of generating nonisomorphic interpretations. At some point, children may hear a sentence such as You didn't put away two toys uttered in a situation that verifies the truth conditions of a non-isomorphic interpretation. That is, such a sentence could be uttered in a situation in which there are two specific toys that the child didn't put away but lots of toys s/he did put away. The pairing between a sentence of this kind and the appropriate situation may provide children with the relevant positive evidence necessary to postulate the existence of the syntactic operations that give rise to non-isomorphic interpretations. On the other hand, if it turns out that children are able to generate non-isomorphic interpretations, albeit with a large computa- 
tional cost, then answering the convergence question amounts to explaining how children's preferences shift over time. One possibility is that as children grow older their computational resources become more adult-like and they eventually manage to access nonisomorphic interpretations more reliably. In this respect, it is interesting to note that a group of 125 -year-old children, tested on the WtNf condition, accepted the puppet's statements, and therefore accessed the wide scope, non-isomorphic interpretation significantly more often than our group of 4-year-olds, i.e. $79 \%$ of the time vs. $33 \%$ of the time, respectively $(t(22)=3.09, P<0.01)$. Statistical analysis also revealed that 5 -year-olds didn't differ significantly from our control group of adults in their acceptance rate of the puppet statements (79 vs. $93 \%$, respectively, $t(22)=1.26, P=0.21$ ). Thus, by 5 years of age, children are able to assign sentences of the form NP didn' $t V$ two $N$ non-isomorphic interpretations in an adult-like fashion (Musolino \& Lidz, 2002). In future research we are planning to address the question of what factors influence the development of the ability to access non-isomorphic interpretations.

Although it is at present unclear why young children experience difficulty with the nonisomorphic interpretation of sentences like NP didn't $V$ two $N$, it is worth pointing out the existence of an interesting parallel between our results and recent findings from the developmental literature. These findings come from a set of studies designed to investigate children's sensitivity to a class of conversational inferences known as scalar implicatures (Carston, 1998; Gazdar, 1979; Grice, 1989; Harnish, 1976; Hirschberg, 1985; Horn, 1972; Levinson, 2000; Sperber \& Wilson, 1995; among many others). Scalar implicatures arise in examples like Some students can write well where the speaker's use of some typically indicates that $\mathrm{s} / \mathrm{he}$ had reasons not to use a more informative term, e.g. all. The sentence, Some students can write well, therefore invites the inference - i.e. gives rise to the implicature - that not all students can write well. Recent work on the development of pragmatics suggests that preschool children are often insensitive to such implicatures when they interpret scalar terms (Chierchia, Crain, Guasti, Gualmini, \& Meroni, 2001; Musolino \& Lidz, in press; Noveck, 2001). For example, using a modal reasoning scenario, Noveck (2001) investigated children's and adults' interpretations of statements expressing $x$ might be $y$ in contexts in which the stronger statements $x$ must be $y$ were true. As Noveck points out, $x$ might be $y$ can be interpreted logically (as compatible with must) or pragmatically (as exclusive to must). What Noveck found is that 7-9-year-old children treated $x$ might be $y$ logically (i.e. as compatible with $x$ must be $y$ ) much more often than adults. Noveck also reports that 8-10-year-old children typically treated French certains ('some') as compatible with tous ('all') whereas adults in the same task were equivocal (for a similar observation with English some, see Smith, 1980 and for similar observations with the disjunction operator, or, see Braine \& Rumain, 1981; Chierchia et al., 2001; Gualmini, Crain, Meroni, Chierchia, \& Guasti, 2001; Paris, 1973). Such behavior has led Noveck to conclude that "younger, albeit competent reasoners, initially treat a relatively weak term logically before becoming aware of its pragmatic potential", and that, in this respect, "children are more logical than adults" (Noveck, 2001, p. 165).

The parallel between children's interpretation of sentences of the form NP didn't V two $N$ and their interpretation of sentences containing scalar terms can now be stated: in both cases, two interpretations are available (logical vs. pragmatic in the scalar experiments and isomorphic vs. non-isomorphic in the experiments reported on here) though young chil- 
dren only seem to be able to access one (the logical interpretation of scalar terms and the isomorphic interpretation of quantified statements). This similarity is sharpened when we take into account the fact that number terms such as two $N$ are typically regarded as belonging to the class of scalar terms (Horn, 1972). Is it possible then that children's difficulty with sentences like $N P$ didn't $V$ two $N$ and their reluctance to interpret scalar terms pragmatically have a common origin? We believe that in spite of the similarities noted above, the case for a uniform treatment of the two phenomena faces a number of difficulties. First, it is important to observe that the phenomenon of scalar implicature typically relies on the existence of entailment relations between the alternative interpretations of scalar terms (e.g. some/all, and/or, might/must, etc.). So for example, All students can write well entails that some students can write well, but not vice-versa. The use of all in All students can write well therefore gives rise to a more informative statement (i.e. one that is true in a narrower set of circumstances) than the one expressed by the proposition Some students can write well. The implicature associated with Some students can write well is therefore typically regarded as arising from a violation of the Gricean maxim of Quantity and in particular the submaxim of informativess given in (i).

Quantity maxim (Grice, 1989)

(i) Make your contribution as informative as required

(ii) Do not make your contribution more informative than is required

An important difference between statements like Some students can write well and Donald didn't find two guys is that in the latter case, as already discussed in the context of Experiment 1, no entailment relation holds between the two scope readings (i.e. not $>$ $t w o$ and $t w o>n o t)$. It is therefore unclear how the relative informative strength of the two scope readings could be defined and therefore how a scalar implicature could arise. The parallelism discussed above further breaks down when we consider the developmental pattern of the respective phenomena. Studies on the development of pragmatic abilities indicate that children as old as 10 still experience difficulty with scalar implicatures (see Noveck, 2001 and references mentioned therein). By contrast, we found that by the age of 5 , children are adult-like in their interpretation of sentences like NP didn't $V$ two $N$. Also note that using the same task as the one we used here, i.e. the TVJT of Crain and Thornton (1998), Chierchia et al. (2001) found that 5-year-olds performed poorly on tasks involving the derivation of scalar implicatures (for similar findings see Musolino \& Lidz, in press). When combined, these observations suggest that the apparent similarity between children's difficulty with scalar implicature and scope ambiguity (in the case of statements like $N P$ didn't $V$ two $N$ ) is only superficial.

\section{Conclusion}

In the field of psycholinguistics, the study of ambiguity resolution has traditionally been used as a tool to investigate the operation of the basic principles underlying the human comprehension system (Fodor, Bever, \& Garrett, 1974; Frazier \& Fodor, 1978; Frazier \& Rayner, 1982; among many others). Here, we have extended this approach to the study of child language and shown that the way young children interpret scopally ambiguous sentences has 
psychological implications for the format of the linguistic representations they entertain and the rules they use to determine the meaning of a sentence from its structure.

More importantly, however, we have used this kind of sentence as a way to find evidence for the hierarchical structure that linguists take to be at the core of grammatical knowledge. While this paper leaves open many important questions concerning the details of children's errors and the path from childhood to linguistic maturity, we have reconfirmed experimentally what every linguist wouldn't doubt: namely, that sentences are built by nesting structures inside of other structures and that relations defined over these structures play an explanatory role not only in the characterization of adult knowledge but also in the characterization of children's knowledge (however incomplete). While children's representations may not always be identical to their adult counterparts, we can be sure that their representations do not differ in kind from the abstract hierarchical structures that best characterize adult representations.

\section{Acknowledgements}

We would like to thank the children and the staff of the following daycare centers without whom none of the research reported here would have been possible: the Center for Young Children at the University of Maryland, the Mulberry Daycare Center and the Schoolhouse Learning Center in the Philadelphia area and the Pushkarini and the Swami Vivekananda preschools in Mysore, India. Special thanks to Susie Metrick and Kirsten Thorpe for assistance with running subjects. We would also like to thank the Central Institute for Indian Languages, especially Omkar Koul, P.P. Giridhar and A.Y. Vijaykumar, for logistical and experimental assistance in Mysore. In addition, we would like to thank audiences at the University of Chicago, the University of Delaware, the University of Massachusetts, Northwestern University, Yale University, the Central Institute of Indian Languages (Mysore), and the Central Institute for English and Foreign Languages (Hyderabad), as well as the audience of the 2000 Boston University Conference on Language Development, for helpful discussions on parts of the material reported here. Finally, our thanks go to our colleagues at the University of Pennsylvania and Northwestern University for their helpful comments and suggestions throughout the elaboration of this work. This work was supported in part by a NIH National Research Service Award Postdoctoral Fellowship to Lidz.

\section{Appendix A}

\section{A.1. Test stories for English}

\section{A.1.1. Wide True, Narrow False Condition}

\section{A.1.1.1. Story 1}

Plot: This story features Cookie Monster and four giant slices of pizza. Cookie Monster is very hungry. He eats the first slice of pizza then he eats the second one but is barely able 
to finish it. Cookie Monster then says that the two remaining slices look good but he's full and can't have another bite to eat.

Puppet's statement: 'Cookie Monster didn't eat two slices of pizza, am I right?'

\section{A.1.1.2. Story 2}

Plot: This story features a brave caveman and four wild horses. The caveman decides that he wants to ride on the horses' backs. He gets on the first horse, rides it and gets thrown to the ground. The same thing happens with the second horse. The caveman then walks to the third and the fourth horses, tells them that he would like to ride on their back but that he won't because he doesn't want to fall again and hurt himself.

Puppet's statement: 'The caveman didn't ride two horses, am I right?'

\section{A.1.1.3. Story 3}

Plot: This takes place at the zoo and features a boy, a giraffe, a kangaroo, a tiger and a cheetah. The boy has always wanted to go to the zoo to pet the animals there. He first approaches the giraffe and pets it. He does the same with the Kangaroo. He then walks to the tiger to try to pet it but the tiger starts growling at the boy and he can't even get close to it. The same thing happens with the Cheetah.

Puppet's statement: 'The boy didn't pet two animals, am I right?'

\section{A.1.1.4. Story 4}

Plot: see Section 4

Puppet's statement: 'Donald didn't find two guys, am I right?'

\section{A.1.2. Wide False, Narrow True Condition}

\section{A.1.2.1. Story 1}

Plot: This story features Cookie Monster and two giant slices of pizza. Cookie Monster is very hungry. He starts eating the first slice of pizza but is barely able to finish it. Cookie Monster then says that the remaining slice looks good but he's full and can't have another bite to eat.

Puppet's statement: 'Cookie Monster didn't eat two slices of pizza, am I right?'

\section{A.1.2.2. Story 2}

Plot: This story features a caveman and two wild horses. The caveman decides that he wants to ride on the horses' backs. He gets on the first horse, rides it and gets thrown to the ground. The caveman then walks to the second horse and tells it that he would like to ride on its back but that he won't because he doesn't want to fall again and hurt himself.

Puppet's statement: 'The caveman didn't ride two horses, am I right?'

\section{A.1.2.3. Story 3}

Plot: This story takes place at the zoo and features a boy, a giraffe and a dinosaur. The boy has always wanted to go to the zoo to pet the animals there. He first approaches the giraffe and pets it. He then walks to the dinosaur to try to pet it but the dinosaur starts growling at the boy and he can't even get close to it.

Puppet's statement: 'The boy didn't pet two animals, am I right?' 


\section{A.1.2.4. Story 4}

Plot: In this story, Donald is playing hide and seek with two of his friends. Donald finds the first friend but he fails to find the second one.

Puppet's statement: 'Donald didn't find two guys, am I right?'

\section{A.2. Control stories for English}

\section{A.2.1. Story 1}

Plot: This story features an old man and three of his friends. After a nice meal at the old man's house, his three friends decide to take a nap on the lawn. Meanwhile, the old man, who isn't tired, decides to mow his lawn. Although he tries to be really careful, the old man hurts two of his friends with his lawnmower.

Puppet's statements: 'The old man hurt two guys, am I right?' (TRUE) or 'The old man didn't hurt any of the guys, am I right?' (FALSE)

\section{A.2.2. Story 2}

Plot: This story features a troll at a Halloween store. The troll is looking at various Halloween items including three pumpkins. He ends up buying one of them but not the two others.

Puppet's statements: 'The troll only bought one pumpkin, am I right?' (TRUE) or 'The troll bought all the pumpkins, am I right?' (FALSE)

\section{A.2.3. Story 3}

Plot: In this story, a hungry cheetah asks his human friend to cook him dinner. The cheetah's friend serves him a hotdog and some peas. The cheetah complains about the peas and says that he won't eat them. He ends up eating only the hotdog.

Puppet's statements: 'The cheetah only ate the hotdog, am I right?' (TRUE)

'The cheetah ate all the food, am I right?' (FALSE)

\section{A.2.4. Story 4}

Plot: In this story, Donald is looking for three rings that were hidden by one of his friends. Donald ends up finding all three rings.

Puppet's statements: 'Donald didn't find all the rings, am I right?' (FALSE) 'Donald found all the rings, am I right?' (TRUE)

\section{A.2.5. Story 5}

Plot: In this story, Minnie is looking at three rings and three balloons that she's considering buying. She ends up buying the rings and two of the three balloons.

Puppet's statements: 'Minnie didn't buy any of the balloons, am I right?' (FALSE) 'Minnie only bought two of the balloons, am I right?' (TRUE) 
A.2.6. Story 6

Plot: In this story, Smurfette is at the pet store. There is a bird, a cat and a dog. Smurfette ends up buying the bird and the cat.

Puppet's statements:

'Smurfette didn't buy the bird, am I right?' (FALSE)

'Smurfette bought a bird and a cat, am I right?' (TRUE)

\section{A.3. Test stories for Kannada}

\section{A.3.1. Wide True, Narrow False Condition}

\section{A.3.1.1. Story 1}

Plot: This story features a boy named Anoop and his four new cars. Anoop wants to wash his cars because he knows it is important to take care of things you like. Today, he washed his first car and then his second car. When he came to the third car, it was already clean because he hadn't driven it yet. The fourth car is a convertible and Anoop is worried about getting water on the inside so he decides not to wash it now.

Puppet's statement: Anoop eradu kaaru toley-al-illa anoop two car wash-inf-neg 'Anoop didn't wash two cars.'

\section{A.3.1.2. Story 2}

Plot: This story features Cookie Monster and four cookies. Cookie Monster is very hungry. He eats the first two cookies. When he comes to the third cookie, he sees that it is shaped like a heart, not a cookie and so even though it has frosting that looks good to eat, he decides not to eat it. The fourth cookie is shaped like a person and he considers eating it but he's not sure if its a cookie or a person so he decides to play it safe and not eat it.

Puppet's statement: avanu eradu biskit tinn-al-illa

he two cookie eat-inf-neg

'He didn't eat two cookies.'

\section{A.3.1.3. Story 3}

Plot: This story features a girl named Rashmi who is planning to make a cake. She has all the ingredients: four eggs, flour, sugar and milk. She puts in the flour, sugar and milk and then she starts to put in the eggs. She puts in two but the other two have black spots on them. They might be rotten so she decides not to use them.
Puppet's statement: Rashmi keeku-ge eradu moTTe haak-al-illa Rashmi cake-dat two egg put-inf-neg 'Rashmi didn't put two eggs into the cake.'

\section{A.3.1.4. Story 4}

Plot: This story features a boy who goes into a store to buy a present for his friend. The 
shopkeeper has 4 rings and the boy has 4 rupees. The first two rings cost 1 rupee each and so he buys them. The second two cost 3 rupees each and so he doesn't have enough money to buy either of them.

Puppet's statement: huduganu eradu ungra karedis-al-illa boy two ring buy-inf-neg

'The boy didn't buy two rings.'

\section{A.3.2. Wide False, Narrow True Condition}

\section{A.3.2.1. Story 1}

Plot: This story features a boy named Anoop and his two new cars. Anoop decides to wash his cars because he knows it is important to take care of things you like. Today, he washes the first car. The second car is a convertible and Anoop is worried about getting water on the inside so he decides not to wash it now.

Puppet's statement: Anoop eradu kaaru toley-al-illa anoop two car wash-inf-neg 'Anoop didn't wash two cars.'

\section{A.3.2.2. Story 2}

Plot: This story features Cookie Monster and two cookies. Cookie Monster is very hungry. He eats the first cookie. When he comes to the second cookie, he sees that it is shaped like a heart, not a cookie and so even though it has frosting that looks good to eat, he decides not to eat it.

Puppet's statement: avanu eradu biskit tinn-al-illa 'He didn't eat two cookies.'

\section{A.3.2.3. Story 3}

Plot: This story features a girl named Rashmi who is planning to make a cake. She has all the ingredients: two eggs, flour, sugar and milk. She puts in the flour, sugar and milk and then she starts to put in the eggs. She puts in one but the other one has a black spot on it. It might be rotten so she decides not to use it.

$\begin{array}{ll}\text { Puppet's statement: } & \text { Rashmi keeku-ge eradu moTTe haak-al-illa } \\ & \text { Rashmi cake-dat two egg put-inf-neg } \\ & \text { 'Rashmi didn't put two eggs into the cake.' }\end{array}$

\section{A.3.2.4. Story 4}

Plot: This story features a boy who goes into a store to buy a present for his friend. The shopkeeper has 2 rings and the boy has 2 rupees. The first ring costs 1 rupee and so he buys it. The second ring costs 3 rupees and so he doesn't have enough money to buy it. 
Puppet's statement: huduganu eradu ungra karedis-al-illa

boy two ring buy-inf-neg

'The boy didn't buy two rings.'

\section{A.4. Control stories for Kannada subjects}

\section{A.4.1. Story 1}

Plot: This story features two lions playing hide and seek. One lion hides in the woods and the other lion turns his head to count. After counting to ten, the lion starts to look for his friend. First he looks behind a tree but there is a snake there. Then he looks behind another tree and there is a snake there too. He decides that there are too many snakes in the woods and so it is too dangerous to play there.

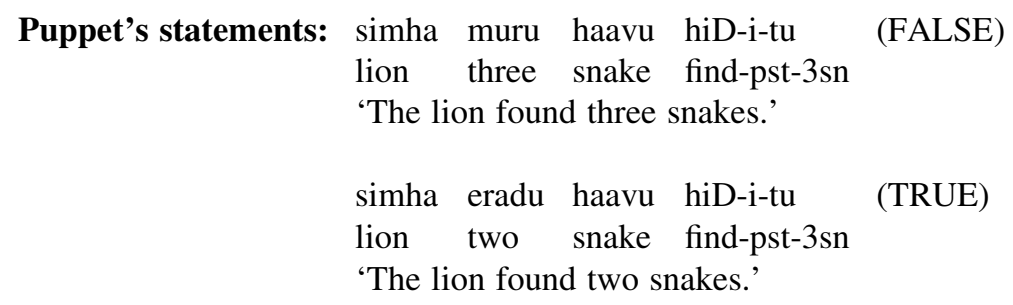

\section{A.4.2. Story 2}

Plot: This story features a very strong man who likes to lift things. He sees a pile of boulders sitting next to a platform and decides to lift the rocks. He lifts the smallest rock first and puts it on the platform. Then he lifts the next bigger rock and puts it on the platform. He has trouble lifting this one because it is very heavy and he is a little tired from lifting the first rock. He tries to lift the third rock but it is much bigger than the others. It won't budge so he gives up.

$\begin{array}{lllll}\text { Puppet's statements: } & \text { ha manushya ella baNDe ett-id-a } & \text { (FALSE) } \\ \text { that man all rock lift-pst-3sm } & \\ \text { 'That man lifted all the rocks.' } & & \\ & & & & \\ \text { ha manushya eradu baNDe ett-id-a } & \text { (TRUE) } \\ \text { that man two rock lift-pst-3sm } & \\ \text { 'That man lifted two rocks.' } & & \end{array}$

\section{A.4.3. Story 3}

Plot: This story features three frogs hopping through the woods. They come upon a house and decide to try to jump over it. The first frog jumps over the house. The second frog also jumps over the house. The third frog has webbed feet and so he says he is not good at jumping over high things. He decides not to try. 


\section{Puppet's statements: ella kappe maney-a meele haar-i-tu (FALSE) all frog house-gen over jump-pst-3sn \\ 'All of the frogs jumped over the house.'

$\begin{array}{lllll}\text { eradu } & \text { kappe } & \text { maney-a } & \text { meele } & \text { haar-i-tu } \\ \text { two frog } & \text { house-gen } & \text { over } & \text { jump-pst-3sn }\end{array}$ \\ (TRUE) \\ 'Two frogs jumped over the house.'}

\section{References}

Barwise, J., \& Cooper, R. (1981). Generalized quantifiers and natural language. Linguistics and Philosophy, 75, $87-106$.

Braine, M., \& Rumain, B. (1981). Children's comprehension of “or": evidence for a sequence of competencies. Journal of Experimental Child Psychology, 31, 46-70.

Brooks, P., \& Braine, M. (1996). What do children know about the universal quantifiers all and each? Cognition, 60, 235-268.

Bucci, W. (1978). The interpretation of universal affirmative propositions: a developmental study. Cognition, 6, 55-77.

Bunt, H. (1985). Mass terms and model-theoretic semantics. Cambridge: Cambridge University Press.

Büring, D. (1997). The great scope inversion conspiracy. Linguistics and Philosophy, 20, 175-194.

Carston, R. (1998). Informativeness, relevance, and scalar implicature. In R. Carston \& S. Uchida (Eds.), Relevance theory: applications and implications (pp. 179-236). Amsterdam: Benjamins.

Chierchia, G., Crain, S., Guasti, M. T., Gualmini, A., \& Meroni, L. (2001). The acquisition of disjunction: evidence for a grammatical view of scalar implicatures. In A. H. J. Do, L. Dominguez \& A. Johansen (Eds.), Proceedings of the 25th annual Boston University conference on language development (pp. 157168). Sommerville, MA: Cascadilla Press.

Chomsky, N. (1957). Syntactic structures. The Hague: Mouton.

Chomsky, N. (1965). Aspects of the theory of syntax. Cambridge, MA: MIT Press.

Chomsky, N. (1981). Lectures on government and binding. Dordrecht: Foris.

Chomsky, N. (1986). Knowledge of language: its nature, origin, and use. New York: Praeger.

Chomsky, N. (1993). A minimalist program for linguistic theory. In K. Hale \& S. J. Keyser (Eds.), The view from building 20 (pp. 1-52). Cambridge, MA: MIT Press.

Chomsky, N. (1995). The minimalist program. Cambridge, MA: MIT Press.

Cooper, R. (1983). Quantification and syntactic theory. Dordrecht: Reidel.

Crain, S. (2000). Sense and sense ability in child language. In S. C. Howell, S. A. Fish \& T. Keith-Lucas (Eds.), Proceedings of the 24th annual Boston University conference on language development. Somerville, MA: Cascadilla Press, pp. 22-44.

Crain, S., \& Thornton, R. (1998). Investigations in universal grammar: a guide to research on the acquisition of syntax and semantics. MIT Press: Cambridge, MA.

Crain, S., Thornton, R., Boster, C., Conway, L., Lillo-Martin, D., \& Woodams, E. (1996). Quantification without qualification. Language Acquisition, 5 (2), 83-153.

de Boysson-Bardies, B., \& Bacri, N. (1977). The interpretation of negative sentences. International Journal of Psycholinguistics, 4, 73-81.

Donaldson, M., \& Lloyd, P. (1974). Sentences and situations: children's judgments of match and mismatch. In F. Bresson (Ed.), Problemes actuels en psycholinguistique. Paris: Centre National de Recherche Scientifique.

Drozd, K., \& Philip, W. (1993). Event quantification in preschoolers' comprehension of negation. In E. V. Clark (Ed.), Proceedings of the 24th annual child language research forum. Stanford, CA: Center for the Study of Language and Information, pp. 72-86.

Fiengo, R. (1977). On trace theory. Linguistic Inquiry, 8, 35-61.

Fodor, J. A., Bever, T., \& Garrett, M. (1974). The psychology of language. New York: McGraw-Hill. 
Fodor, J. D. (1982). The mental representation of quantifiers. In S. Peters \& E. Saarinen (Eds.), Processes, beliefs, and questions (pp. 129-164). Dordrecht: Reidel.

Frazier, L. (2000). On interpretation: minimal lowering. In M. W. Crocker, M. Pickering \& C. Clifton Jr. (Eds.), Architectures and mechanisms for language processing (pp. 303-323). Cambridge: Cambridge University Press.

Frazier, L., \& Fodor, J. D. (1978). The sausage-machine: a new two-stage parsing model. Cognition, 6, 291-328.

Frazier, L., \& Rayner, K. (1982). Making and correcting errors during sentence comprehension: eye movements in the analysis of structurally ambiguous sentences. Cognitive Psychology, 14, 178-210.

Frege, G. (1892). On sense and nominatum. Reprinted in A. P. Martinich (Ed.), The philosophy of language. Oxford: Oxford University Press (1990).

Gazdar, G. (1979). Pragmatics. New York: Academic Press.

Grice, P. (1989). Studies in the way of words. Cambridge, MA: Harvard University Press.

Grodzinsky, Y., \& Reinhart, T. (1993). The innateness of binding and coreference. Linguistic Inquiry, 24 (1), 69101.

Gualmini, A., Crain, S., Meroni, L., Chierchia, G., \& Guasti, M. T. (2001). At the semantics/pragmatics interface in child language. In R. Hastings, B. Jackson \& Z. Zvolenszky (Eds.), Proceedings of SALT XIIthaca, NY: Cornell University.

Harnish, R. (1976). Logical form and implicature. In T. Bever, J. Katz \& T. Langedoen (Eds.), An integrated theory of linguistic ability (pp. 313-391). New York: Crowell.

Hirschberg, J. (1985). A theory of scalar implicature. Doctoral dissertation, University of Pennsylvania, Philadelphia.

Horn, L. (1972). On the semantic properties of the logical operators in English. Doctoral dissertation, UCLA (Distributed by IULC, Indiana University, Bloomington).

Horn, L. R. (1989). A natural history of negation. Chicago, IL: University of Chicago Press.

Hornstein, N. (1984). Logic as grammar. Cambridge, MA: MIT Press.

Huang, C.-T. J. (1982). Logical relations in Chinese and the theory of grammar. Doctoral dissertation, MIT, Cambridge, MA.

Inhelder, B., \& Piaget, J. (1958). The growth of logical thinking from childhood to adolescence, New York: Basic Books.

Inhelder, B., \& Piaget, J. (1964). The early growth of logic in the child. London: Routledge.

Jackendoff, R. (1972). Semantic interpretation in generative grammar. Cambridge, MA: MIT Press.

Johnson-Laird, P. (1969). On understanding logically complex sentences. Quarterly Journal of Experimental Psychology, 21, 1-13.

Keenan, E., \& Stavi, J. (1986). A semantic characterization of natural language determiners. Linguistics and Philosophy, 9, 253-326.

Krämer, I. (2000). Interpreting indefinites: an experimental study of children's language comprehension. Doctoral dissertation, MPI Series in Psycholinguistics.

Kroch, A. (1974). The semantics of scope in English. PhD dissertation, MIT, Cambridge, MA.

Kurtzman, H., \& MacDonald, M. (1993). Resolution of quantifier scope ambiguities. Cognition, 48, 243-279.

Lasnik, H. (1976). Remarks on Coreference. Linguistic Analysis, 2, 1-21.

Levinson, S. (2000). Presumptive meanings. Cambridge, MA: MIT Press.

Lidz, J. (1999). The morphosemantics of object case in Kannada. In S. Bird, A. Carnie, J. D. Haugen \& P. Norquest (Eds.), Proceedings of the 18th west coast conference on formal linguistics (pp. 325-336). Somerville, MA: Cascadilla Press.

May, R. (1977). The grammar of quantification. Doctoral dissertation, MIT, Cambridge, MA.

May, R. (1985). Logical form. Cambridge, MA: MIT Press.

McCawley, J. (1970). Where do noun phrases come from? In R. Jacobs \& P. Rosenbaum (Eds.), Readings in English transformational grammar. Waltham, MA: Ginn.

Musolino, J. (in press). Structure and meaning in the acquistion of scope. In L. Frazier, T. Roeper \& K. Wexler (Eds.), Studies in Theoretical Psycholinguistics Acquisition meets Semantics. Kluwer: Academic Press.

Musolino, J., Crain, S., \& Thornton, R. (2000). Navigating negative quantificational space. Linguistics, 38 (1), 132.

Musolino, J., \& Lidz, J. (2002). Why children aren't universally sucessful with quantification, Indiana University and Northwestern University, in preparation. 
Musolino, J., \& Lidz, J. (in press). Preschool logic: truth and felicity in the acquisition of quantification. In B. Skarabela, S. Fish, \& A. H. J. Do (Eds.), Proceedings of 26th annual Boston University conference on language development. Sommerville, MA: Cascadilla Press.

Noveck, I. (2001). When children are more logical than adults: experimental investigations of scalar implicature. Cognition, 78, 165-188.

O'Leary, C., \& Crain, S. (1994). Negative polarity items (a positive result), positive polarity items (a negative result). Paper presented at the 1994 Boston University conference on language development, Boston, MA.

Paris, S. (1973). Comprehension of language connectives and propositional logical relationships. Journal of Experimental Child Psychology, 16, 278-291.

Philip, W. (1995). Event quantification in the acquisition of universal quantification. Doctoral dissertation, University of Massachusetts, Amherst.

Philip, W. (1996). The event quantificational account of symmetrical interpretation and a denial of implausible infelicity. In A. Stringfellow, D. Cahana-Amitay, E. Hughes \& A. Zukowski (Eds.), Proceedings of the 20th annual Boston University conference on language development (pp. 564-575). Somerville, MA: Cascadilla Press.

Philip, W., \& Aurelio, S. (1991). Quantifier spreading: pilot study of preschooler's “every”. In T. Maxfield \& B. Plunkett (Eds.), Papers in the acquisition of WH: proceedings of the Umass Roundtable, May 1990. Amherst, MA: Graduate Linguistics Students Association, Linguistics Department, UMASS, pp. 267-281.

Pollard, C., \& Sag, I. (1994). Head driven phrase structure grammar. Chicago, IL: University of Chicago Press.

Reinhart, T. (1976). The syntactic domain of anaphora. Doctoral dissertation, MIT, Cambridge, MA.

Reinhart, T. (1983). Anaphora and Semantic Interpretation, London. Croon Helm.

Reinhart, T. (1995). Interface strategies (OTS working papers, TL-95-002), Utrecht University.

Reinhart, T. (1997). Quantifier scope: how labor is divided between QR and choice functions. Linguistics and Philosophy, 20, 335-397.

Roeper, T., \& Matthei, E. (1975). On the acquisition of all and some. Papers and reports on child language development, 9. Stanford, CA: Stanford University Press.

Smith, C. L. (1980). Quantifiers and question answering in young children. Journal of Experimental Child Psychology, 30, 191-205.

Sperber, D., \& Wilson, D. (1995). Relevance: communication and cognition. (2nd ed.) Cambridge, MA: Harvard University Press.

Steedman, M. (1987). Combinatory grammars and parasitic gaps. Natural Language and Linguistic Theory, 5, $403-440$.

Tanenhaus, M. K., \& Trueswell, J. C. (1995). Sentence comprehension. In J. L. Miller \& P. D. Eimas (Eds.), Handbook of perception and cognition: speech, language, and communication (2nd ed.). (pp. 217-262). San Diego, CA: Academic Press.

Thornton, R. (1995). Children's negative questions: a production/comprehension asymmetry. In J. Fuller, H. Han \& D. Parkinson (Eds.), Proceedings of the Eastern States Conference on Linguistics. Ithaca, NY: Cornell University Press.

Trueswell, J. C., Sekerina, I., Hill, N., \& Logrip, M. (1999). The kindergarten-path effect: studying on-line sentence processing in young children. Cognition, 73, 89-134.

van Benthem, J. (1986). Essays in logical semantics. Dordrecht: D. Reidel. 